\title{
Lack of Parkin Anticipates the Phenotype and Affects Mitochondrial Morphology and mtDNA Levels in a Mouse Model of Parkinson's Disease
}

\author{
@Milena Pinto, ${ }^{1}$ - Nadee Nissanka, ${ }^{2}$ and ${ }^{\circledR C}$ Carlos T. Moraes ${ }^{1,2}$ \\ ${ }^{1}$ Department of Neurology and ${ }^{2}$ Neuroscience Program, Miller School of Medicine, University of Miami, Miami, Florida 33136
}

\begin{abstract}
PARK2 is the most common gene mutated in monogenic recessive familial cases of Parkinson's disease (PD). Pathogenic mutations cause a loss of function of the encoded protein Parkin. ParkinKO mice, however, poorly represent human PD symptoms as they only exhibit mild motor phenotypes, minor dopamine metabolism abnormalities, and no signs of dopaminergic neurodegeneration. Parkin has been shown to participate in mitochondrial turnover, by targeting damaged mitochondria with low membrane potential to mitophagy. We studied the role of Parkin on mitochondrial quality control in vivo by knocking out Parkin in the PD-mito-PstI mouse (males), where the mitochondrial DNA (mtDNA) undergoes double-strand breaks only in dopaminergic neurons. The lack of Parkin promoted earlier onset of dopaminergic neurodegeneration and motor defects in the PD-mito-PstI mice, but it did not worsen the pathology. The lack of Parkin affected mitochondrial morphology in dopaminergic axons and was associated with an increase in mtDNA levels (mutant and wild type). Unexpectedly, it did not cause a parallel increase in mitochondrial mass or mitophagy. Our results suggest that Parkin affects mtDNA levels in a mitophagy-independent manner.
\end{abstract}

Key words: deletion; double-strand breaks; mitochondria; mitophagy; mtDNA; Parkinson

Significance Statement

Parkinson's disease is characterized by progressive motor symptoms due to the selective loss of dopaminergic neurons in the substantia nigra. Loss-of-function mutations of Parkin cause some monogenic forms of Parkinson's disease, possibly through its role in mitochondrial turnover and quality control. To study whether Parkin has a role in vivo in the context of mitochondrial damage, we knocked out Parkin in a mouse model in which the mitochondrial DNA is damaged in dopaminergic neurons. We found that the loss of Parkin did not exacerbate the parkinsonian pathology already present in the mice, but it was associated with an increase in mtDNA levels (mutant and wild-type) without altering mitochondrial mass. These results shed new light on the function of Parkin in vivo.

\section{Introduction}

Parkinson's disease (PD) is the second most common progressive neurodegenerative disease after Alzheimer's disease. The classical motor symptoms are caused by striatal dopamine (DA) deple-

Received May 19, 2017; revised Aug. 24, 2017; accepted Oct. 3, 2017.

Author contributions: M.P., N.N., and C.T.M. designed research; M.P. and N.N. performed research; M.P., N.N., and C.T.M. analyzed data; M.P., N.N., and C.T.M. wrote the paper.

This work was supported in part by National Institutes of Health (NIH) Grants 1R01-AG-036871, 1R01-NS079965, and 5R01-EY-010804 (to C.T.M.), Parkinson's Disease Foundation Fellowship PDF-FBS-1316 (to M.P.), and American Heart Association Fellowship 16 PRE30480009 and Lois Pope LIFE Fellows Program (to N.N.). Support was also received by National Eye Institute Center Grant P30-EY-014801 and from the NIH.

The authors declare no competing financial interests.

Correspondence should be addressed to either of the following: Milena Pinto, 1420 NW 9th Avenue, TSL Building Room 231, Miami, FL 33136, E-mail: mpinto@med.miami.edu; or Carlos T. Moraes, 1420 NW 9th Avenue, TSL Building Room 229, Miami, FL 33136, E-mail: cmoraes@med.miami.edu.

DOI:10.1523/JNEUROSCI.1384-17.2017

Copyright $\odot 2018$ the authors $\quad 0270-6474 / 18 / 381042-12 \$ 15.00 / 0$ tion, consequent to the progressive loss of dopaminergic neurons in the substantia nigra (SN; Dauer and Przedborski, 2003; Braak et al., 2004).

Over the last few decades, increasing relevance has been given to the role that mitochondrial defects play in the etiology of PD. Disruption of oxidative phosphorylation (OXPHOS), particularly Complex I, is believed to contribute to neuronal loss in PD (Schapira et al., 1990a,b). Nigrostriatal dopaminergic neurons in both PD and aged individuals also show Complex IV dysfunctions (Bender et al., 2006; Kraytsberg et al., 2006) and reduction of Complex I and Complex II subunits (Grünewald et al., 2016). Mitochondrial DNA (mtDNA) is also affected in PD patients: dopaminergic neurons in both individuals with $\mathrm{PD}$ and aged individuals have high levels of mtDNA deletions (Bender et al., 2006; Kraytsberg et al., 2006); single dopaminergic neurons from PD patients with Complex I and II defects, show low abundance 
of the mtDNA transcription factors TFAM (transcription factor $\mathrm{A}$, mitochondrial) and TFB2M (mitochondrial transcription factor B2; Grünewald et al., 2016). Moreover, patients harboring mutations in polymerase $\gamma$, which cause mtDNA abnormalities, exhibit dopaminergic neurodegeneration and Lewy body accumulation (Reeve et al., 2013).

PARK2 is one of the genes mutated in the rare cases of familial PD (Kitada et al., 1998), and its mutations are the most frequent cause of autosomal recessive, early-onset, and juvenile PD. Parkin, its encoded protein, is also downregulated in sporadic PD, supporting its importance in the pathophysiology of this disease (LaVoie et al., 2005; Shin et al., 2011). Parkin is a ubiquitin ligase involved in many mitochondrial pathways, as follows: it induces the clearance of dysfunctional mitochondria through mitophagy (Koh and Chung, 2010; Narendra and Youle, 2011), it influences mitochondrial biogenesis by ubiquitination of PARIS (PGC- $1 \alpha$ [Peroxisome proliferator-activated receptor gamma coactivator 1-alpha] transcriptional repressor; Lee et al., 2017); and it can regulate mitochondrial movement by regulating Miro (Wang et al., 2011; Gaweda-Walerych and Zekanowski, 2013). The crucial role of Parkin in mitochondrial functions has been extensively demonstrated in vitro, but in vivo studies have been less conclusive, with controversial results depending on the animal model involved. Parkin mutant Drosophila displays flight muscle defects, locomotive behavioral problems, male sterility, and reduced life span (Greene et al., 2003). Parkin mutant flies are also more susceptible to oxidative stress, some dopaminergic neurons display shrinkage and abnormal morphology, and mitochondria are defective and swollen in muscle cells (Pickrell and Youle, 2015). On the other side, ParkinKO mice do not show typical signs of PD, including motor phenotypes, DA metabolism abnormalities, or nigrostriatal degeneration (Goldberg et al., 2003; Perez and Palmiter, 2005; Kitada et al., 2009). Accordingly, ParkinKO mice do not have significant mitochondrial defects (Damiano et al., 2014). One possible explanation for this phenomenon is that a compensatory or an alternative mitochondrial quality control mechanism takes over during development. The fact that nigrostriatal degeneration does occur whether Parkin is conditionally silenced after birth validates this hypothesis (Shin et al., 2011). Another possibility is that age-related factors make it difficult to reproduce the human phenotype in mice. Both genetic and environmental factors influence the development of $\mathrm{PD}$, and aging is the most important risk factor in PD. mtDNA damage also accumulates with aging, so the short life span of a mouse would not allow for the accumulation of mitochondrial dysfunction, which normally occurs in patients (Bratic and Larsson, 2013). ParkinKO mice would not recapitulate PD phenotypes because they lack the pathogenic process of human aging and, in particular, the accumulation of damaged mtDNA in dopaminergic neurons. To investigate this possibility, we knocked out Parkin in the PD-mito-PstI mouse, where mtDNA damage accumulates specifically in dopaminergic neurons. Using this genetic mouse model, we combined a heritable cause of PD (Parkin loss of function) with an acquired insult (mtDNA damage) that has been observed in normal aging.

\section{Materials and Methods}

Animals. All mice procedures were performed according to a protocol approved by the University of Miami. Mice were housed in a virus antigen-free facility at the University of Miami in a $12 \mathrm{~h} \mathrm{light/dark} \mathrm{cycle}$ at room temperature and fed ad libitum with a standard rodent diet.

The generation of PD-mito-PstI transgenic was previously described (Pickrell et al., 2011a). Briefly, a mammalian version of the bacterial PstI gene was positioned downstream of a $5^{\prime}$ mitochondrial targeting sequence from human COX VIII gene (cytochrome $c$ oxidase subunit VIII). The intervening sequence 8 (IVS8) was introduced between the tetracycline response element (TRE) promoter sequence and the mitoPstI coding sequence. Mice were crossed with transgenic mice harboring one allele for a dopamine transporter (DAT)-driven tetracycline transactivator (tTA) protein (Cagniard et al., 2006). PD-mito-PstI animals with or without Parkin were always compared with control animals harboring the DAT-tTA allele with or without Parkin $\left(\mathrm{DAT}^{+}{ }^{\mathrm{Pst} \mathrm{I}^{-}}{ }^{-}\right.$).

PD-mito-PstI mice were crossed with ParkinKO mice [B6.129S4Park2tm1Shn/J (https://www.jax.org/strain/006582), The Jackson Laboratory] in which most of exon 3 was replaced in frame by the coding sequence of EGFP. Exon 3 skipping causes a missense mutation and premature termination at a stop codon in exon 5 following 49 additional out-of-frame amino acid residues (Goldberg et al., 2003). The nuclear background of all the mouse models described here was C57BL/6J (backcrossed at least 10 generations). Male mice were used in this study.

For the mitochondrial morphology studies, mice were crossed with mito-eYFP mice that express a TRE promoter-regulated mitochondrial-targeted enhanced yellow fluorescent protein [eYFP; Chandrasekaran et al., 2006; C57BL/6-Tg(tetO-COX8A/EYFP)1Ksn/J (https://www. jax.org/strain/006618), The Jackson Laboratory].

Pole test. Pole test for motor coordination/nigrostriatal dysfunction of mice was previously described (Matsuura et al., 1997). Animals were hung upright on a vertical (diameter, $8 \mathrm{~mm}$; length, $55 \mathrm{~mm}$ ) pole and were given 3 min to change orientation and descend. Animals were given three trials, and the average latency to descend to the base was recorded. Failure to descend or fall from the pole was given a maximum time of 3 min.

Rotarod. Motor coordination was evaluated with a Rotarod (IITC Life Science) designed for mice. Animals were tested with three runs on a given day with one run for practice. A resting period of $120 \mathrm{~s}$ between each run was given. Animals were required to position limbs to stay on a rotating rod accelerating from 6 to $20 \mathrm{rpm}$ over a $180 \mathrm{~s} \mathrm{time} \mathrm{period.} \mathrm{Mice}$ that completed the task received a final latency time of $180 \mathrm{~s}$.

Activity monitoring. Spontaneous self-initiated movement was recorded using an activity cage setup (Columbus Instruments) designed for mice. Animals were housed individually in a clean cage environment $30 \mathrm{~min}$ before their dark cycle and then monitored for a $12 \mathrm{~h}$ period undisturbed. Ambulatory movement was defined by the number of infrared beam breaks that occurred inside of the cage for each $30 \mathrm{~min}$ period recorded.

Open field test. Open field (Med Associates) consists of a chamber and a system of 16 infrared transmitters that record the position of the animal in the three-dimensional space. With this system, we recorded the horizontal movement and the rearing activity. Animals were placed in the chamber $30 \mathrm{~min}$ before the test, and the locomotor activities were recorded for $15 \mathrm{~min}$.

Stereological neuron counting. Anesthetized mice were killed using cervical dislocation. Brains were isolated, and the regions of interest were dissected using a Mouse Brain Slicer Matrix (for midbrain, the region between -1 and $-4 \mathrm{~mm}$ from bregma; for striatum, the region between -1 and $+3 \mathrm{~mm}$ from bregma). Brain segments were submerged in $4 \%$ paraformaldehyde (PFA) at $4^{\circ} \mathrm{C}$ overnight and then cryoprotected in a $30 \%$ sucrose solution. Brains were embedded in Tissue-Tek O.C.T. compound (Sakura) and frozen by submersion into 2-methylbutane cooled in liquid nitrogen. Sections were cut on a cryostat (30 $\mu \mathrm{m}$ sections were used), and, starting from bregma $-1 \mathrm{~mm}$, the first 30 slides were discarded. Dopaminergic neurons were counted in every fifth section, with 10-12 total sections counted per individual animal. Slides were permeabilized with $0.4 \%$ Triton X-100, blocked for $1 \mathrm{~h}$ at room temperature with normal goat serum (KPL), and incubated with primary antibody (Ab) anti-tyrosine hydroxylase (TH; catalog \#T1299, Sigma-Aldrich; RRID:AB_477560) at 1:500. Secondary mouse-conjugated HRP antibody (KPL) was used for $1 \mathrm{~h}$ at room temperature. Slides were subsequently incubated with streptavidin-peroxidase (KPL) for $30 \mathrm{~min}$, visualized with $0.05 \%$ diaminobenzidine (DAB) for $7 \mathrm{~min}$, and mounted with glycerol. 
Stereology workstation program (StereoInvestigator, MicroBrightField) was used to quantify $\mathrm{TH}^{+}$neurons. According to the program, we set a guard zone of $3 \mu \mathrm{m}$ from the top and from the bottom of each section that was not considered in the counting. The A9 area was outlined using the $10 \times$ objective, and neurons were counted at $60 \times$ magnification on an Olympus BX51 Microscope. A scan grid size was determined to have at least 10 grid sites per section. The estimated numbers of dopaminergic neurons were calculated by counting $\mathrm{TH}^{+}$cells present in the unbiased virtual inclusion counting frames. We accepted a coefficient of error (Gundersen) of $<0.15$.

Western blotting. Protein extracts were prepared from isolated striatum samples homogenized with a hand-held rotor (VWR) in PBS containing a protease inhibitor cocktail (Roche). Samples were then snap frozen twice in liquid nitrogen and stored at $-80^{\circ} \mathrm{C}$ until use. Upon use, SDS was added to the homogenate at a final concentration of $4 \%$. Homogenates were then sonicated and centrifuged at 10,000 $\times g$ for $5 \mathrm{~min}$, and the supernatant was collected for analysis. Proteins were run on 4-20\% SDS-polyacrylamide gradient gel (Bio-Rad). The gel was blotted on polyvinylidene fluoride (Bio-Rad) membrane. Membranes were blocked in 1:1 Odyssey blocking solution (LI-COR) for $1 \mathrm{~h}$ at room temperature.

Primary antibodies used were as follows: mouse anti-TH 1:1000 dilution (catalog \#T1299, Sigma-Aldrich; RRID:AB_477560), rabbit anti-DAT 1:1000 (catalog \#D6944, Sigma-Aldrich; RRID:AB_1840807), mouse $\alpha$-tubulin 1:2000 (catalog \#T9026, Sigma-Aldrich; RRID:AB_477593), rabbit anti-MAO 1:1000 (catalog\#M1821, Sigma-Aldrich; RRID:AB_1841010), mouse anti COMT 1:1000 (catalog \#611970, BD Biosciences; RRID: AB_399391), rabbit anti-Porin 1:2000 (catalog \#4866, Cell Signaling Technology; RRID:AB_2272627), mouse anti OXPHOS cocktail 1:1000 (catalog \#ab110413, Abcam; RRID:AB_2629281), rabbit $\beta$-actin 1:5000 (catalog \#A2066, Sigma-Aldrich; RRID:AB_476693), mouse anti p62 1:1000 (catalog \#ab56416, Abcam; RRID:AB_945626), rabbit anti-LC3b 1:1000 (catalog \#2775 and \#2775S, Cell Signaling Technology; RRID: AB_915950), optic atrophy protein 1 (OPA1; catalog \#612606, BD Biosciences; RRID:AB_399888), Mitofusin 2 (Mfn2; catalog \#Ab56889, Abcam; RRID:AB_2142629), Tim23 (catalog \#611222, BD Biosciences; RRID:AB_398754), PARIS (catalog \#MABN476, Sigma-Aldrich; RRID: AB_2688024). Secondary antibodies used were infrared-conjugated antibodies anti-rabbit-700/anti-mouse-800 (Rockland) at 1:3000 to 1:5000 concentrations, respectively, and incubated at room temperature for $1 \mathrm{~h}$.

Blots were visualized with an Odyssey Infrared Imaging System (LICOR). Optical density measurements were taken by default software supplied by LI-COR on blots.

Dopamine and metabolite quantification. Dopamine and metabolite quantification measurements were performed at the Vanderbilt University Neurochemistry Core Laboratory. Neurotransmitter and metabolite levels were normalized to total protein. Determinations were achieved using two dedicated Waters high-performance liquid chromatography systems equipped with autosamplers and a Decade II electrochemical detector.

Laser capture microdissection. Twenty micrometer sections were immunostained for TH (catalog \#T1299, Sigma-Aldrich; RRID: AB_477560) using HRP-conjugated secondary Ab and chromogenic substrate (DAB). After dehydration, they were cleared with xylenes and air dried. Sections were dried overnight in a chamber with desiccant chips ( $1 \mathrm{~g}$ each). $\mathrm{TH}^{+}$ neurons in the $\mathrm{SN}$ region were pooled from 10 slides per animal using an LMD Laser Microdissection Microscope (Leica). DNA was extracted using the QIAmp DNA Micro Kit (Qiagen).

Real-time PCR. Total DNA was extracted with standard phenol/chloroform/ethanol precipitation from striatum and from midbrain. To determine the relative quantity of mtDNA in each sample, we used the comparative Ct method (Schmittgen and Livak, 2008) normalizing to a genomic DNA region. To estimate the levels of total mtDNA (full-length and recombined), we designed primers to amplify mtDNA regions distal to both PstI sites (COXI F, AGGCTTCACCCTAGATGACACA; COXI R, GTAGCGTCGTGGTATTCCTGAA; and ND1 F, CAGCCTGACCCA TAGCCATA; ND1 R, ATTCTCCTTCTGTCAGGTCGAA). To determine the relative quantity of only the full-length mtDNA in each sample, we designed primers to amplify an mtDNA region inside PstI sites (ND4
F, GGAACCAAACTGAACGCCTA; ND4 R, ATGAGGGCAATTAGC AGTGG). Primers for genomic DNA were as follows: $\beta$-Actin F, GCG CAAGTACTCTGTGTGGA; and $\beta$-Actin R, CATCGTACTCCTGCT TGCTG.

For quantification of mito-PstI deletions (recombinant mtDNA), we used primers flanking the PstI breakpoint, normalized for primers amplifying an mtDNA region not affected by the Pst $\mathrm{I}$ cleavage as follows: Pst $\mathrm{I}$ F, TTGCCCACTTCCTTCCACAAG; Pst I R, GATGTCTCCGATG CGGTTAT.

Targets were amplified with SsoAdvanced Universal SYBR Green Supermix (Bio-Rad) using the CFX96 Realtime PCR system (Bio-Rad) under specified manufacturer conditions. Relative quantity was corrected for relative PCR amplification efficiency using Bio-Rad CFX Manager Software.

Southern blotting. Two micrograms of total DNA was digested with EagI HF (NEB), separated on $0.7 \%$ agarose gel, and transferred to a Zeta-probe GT Membrane (Bio-Rad). Probes to detect mtDNA were amplified from genomic DNA isolated from striata of a C57BL/6J wildtype mouse with Q5 Hot Start High-Fidelity DNA Polymerase (NEB). Primers used to amplify the mtDNA probe, as follows: 15660 F, CTATC CCCTTCCCCATTTGGTCTATTAAT; and 1078 R, GTCATGAAATCT TCTGGGTGTAGG.

The following primers were used to amplify the nuclear DNA probe: 18S F, CCCGGGGAGGTAGTGACGAAAAAT; and 18S R, CCGGAC ATCTAAGGGCATCACAG.

Amplified DNA was purified, labeled with $\left[\alpha^{-}{ }^{32} \mathrm{P}\right] \mathrm{dCTP}$ using a Random Primed DNA Labeling Kit (Roche Applied Science) and cleaned with G-50 Sephadex Quick Spin Columns (GE Healthcare). Detection and densitometric quantification of mtDNA and $18 \mathrm{~S}$ recombinant DNA signals was performed with the Cyclone Plus Phosphor Imager equipped with the Optiquant software (PerkinElmer).

Long-range PCR. Long-range PCR to detect DNA lesions followed the protocol of Furda et al. (2012). In brief, striatal DNA was isolated using a DNeasy Blood and Tissue Kit (Qiagen). Five hundred nanograms of DNA was digested for $2 \mathrm{~h}$ with HaeII enzyme at $37^{\circ} \mathrm{C}$ to linearize mtDNA. Fifteen nanograms of DNA was amplified to generate a $10 \mathrm{~kb}$ fragment using a Long-Range PCR Polymerase (Takara). Values from $10 \mathrm{~kb}$ amplification were normalized to values from a $117 \mathrm{bp}$ mtDNA product.

The primers for $10 \mathrm{kB}$ fragment amplification were as follows: $3278 \mathrm{~F}$, GCCAGCCTGACCCATAGCCATAATAT; and 13337 R, GAGAGATTT TATGGGTGTAATGCGG.

The primers for $117 \mathrm{bp}$ fragment amplification were as follows: $13597 \mathrm{~F}$, CCCAGCTACTACCATCATTCAAGT; and 13688 R, GATGGTTTGG GAGATTGGTTGATGT.

Mitochondrial counting analysis. FIJI software was used to evaluate mitochondrial size and number in dopaminergic axons. Mice expressing mito-eYFP were perfused with 4\% PFA, brains were removed, and $50 \mu \mathrm{m}$ sections were cut with a vibratome. Z-stack images were taken at $40 \times$ with a minimum of 10 layers per figure. The Z-stack file was then opened in FIJI. An overlay of the images was created and converted to 8 bit, and the colors were inverted. Threshold was set at 230 . Single axons were selected freehand, and particles were analyzed (size 1 to infinity). Neurite length was then measured with the Simple Neurite Tracer plugin. Mitochondria numbers were normalized per axon length. Mitochondria sizes were divided into four groups $\left(1-5,5-10,10-20\right.$, and $\left.>20 \mu \mathrm{m}^{2}\right)$. Three to five neurites were analyzed per slice, and three to five slices were analyzed per mouse with a range of particles/mouse between 243 and 750 .

Experimental design and statistical analysis. The experimental design for different experiments is described in the previous subsections. Post hoc power for behavioral studies was 0.66. A one-way ANOVA was performed for multiple comparisons with Tukey post hoc analysis; $p \leq 0.05$ determined significance. When two groups of animals were compared, a $t$ test was performed (indicated as a "T" in the figures). The number of observations per animal used in each experimental series was included in the figure legends $\left({ }^{*} p<0.05,{ }^{* *} p<0.01,{ }^{* *} p<0.005\right)$. The exact $p$ values were indicated in the manuscript. GraphPad (GraphPad Software) was used to perform statistical analysis. Detailed statistical analyses are described in Figures 1-2 available at https://doi.org/10.1523/JNEUROSCI.1384-17.2017.f1-2, 1-3 available at https://doi.org/10.1523/JNEUROSCI.1384-17.2017.f1-3, 
A

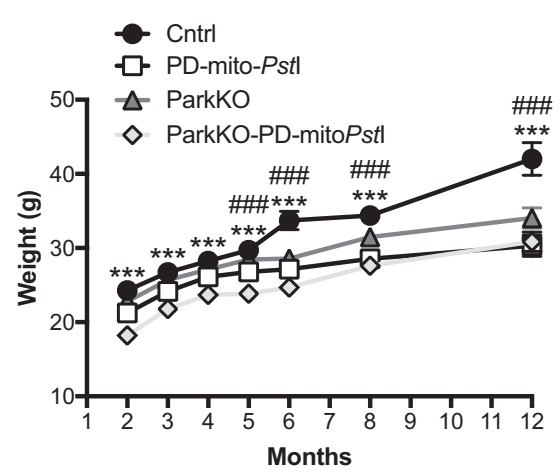

B
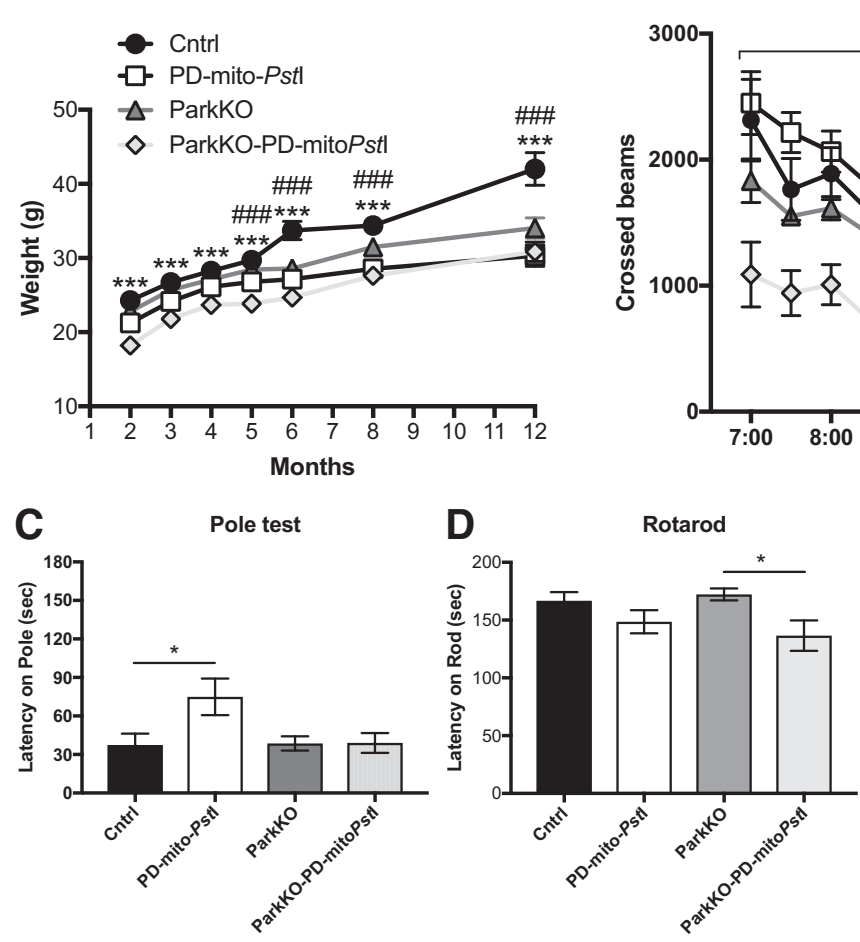

iss

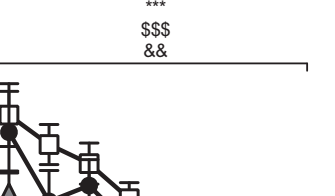

Activity cage

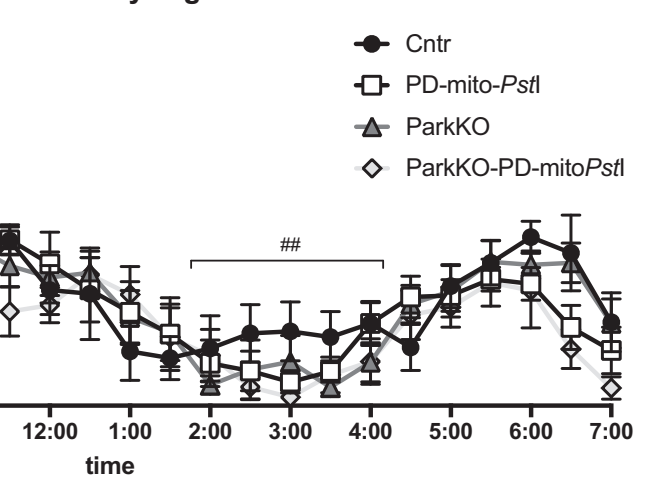

E

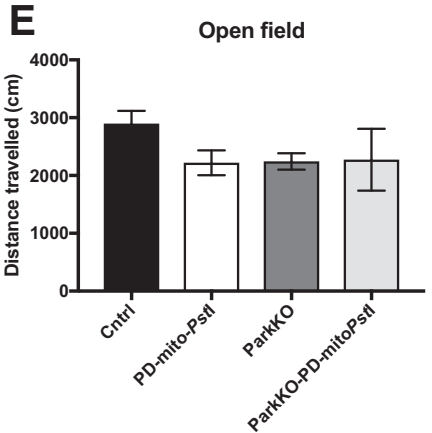

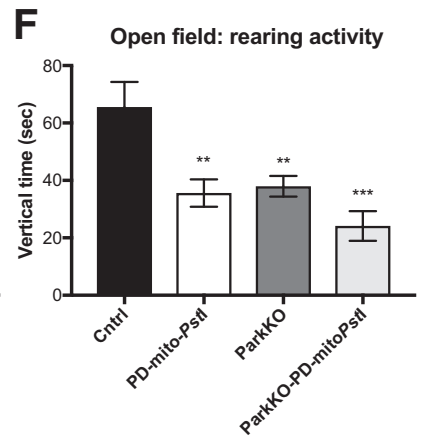

Figure 1. Locomotive phenotypes in ParkinKO PD-mito-Pstl mice. A, Weight measurements (grams) taken at 2, 4, 8, and 12 months of age ( $n=15 /$ group). Error bars \pm SEM (statistics are detailed in Fig. 1-2). B, Locomotive activity of 2-month-old animals measured by the number of beam breaks that occurred in an activity cage during nocturnal hours (12 h; $n=6-8 / \mathrm{group})$. Error bars \pm SEM. * ${ }^{*}$ (ntrl/ParkKO-PD-mitoPstl, \#Cntrl/PD-mitoPstl, \$PD-mitoPst//ParkKO-PD-mitoPstl, \&ParkK0/ParkKO-PD-mitoPstl (statistics are detailed in Fig. 1-3 available at https://doi.org/10. 1523/JNEUROSCI.1384-17.2017.f1-3). C $-\boldsymbol{F}$, Coordination tests performed on 2-month-old animals: pole test ( $n=14-23 /$ group; $\boldsymbol{C})$; Rotarod $(n=7-9 /$ group; $\boldsymbol{D})$; open field, measurement of total distance traveled on a $15 \mathrm{~min}$ period $(n=7-10 / \mathrm{group} ; \boldsymbol{E})$; and open field, measurement of rearing activity $(n=7-10 ; \boldsymbol{F}$; statistics are detailed in Fig. 1-4 available at https://doi.org/10.1523/ JNEUROSCI.1384-17.2017.f1-4). ${ }^{*} p<0.05,{ }^{* *} p<0.01,{ }^{* * *} p<0.001$. Figure 1-1 available at https://doi.org/10.1523/JNEUROSCI.1384-17.2017.f1-1 describes the same behavioral analyses in older mice (statistics are detailed in Fig. 1-5 available at https://doi.org/10.1523/JNEUROSCI.1384-17.2017.f1-5).

1-4 available at https://doi.org/10.1523/JNEUROSCI.1384-17.2017.f1-4, 1-5 available at https://doi.org/10.1523/JNEUROSCI.1384-17.2017.f1-5, 3-2 available at https://doi.org/10.1523/JNEUROSCI.1384-17.2017.f3-2, 4-2 available at https://doi.org/10.1523/JNEUROSCI.1384-17.2017.f4-2, 4-3 available at https://doi.org/10.1523/JNEUROSCI.1384-17.2017.f4-3, and 5-1 available at https://doi.org/10.1523/JNEUROSCI.1384-17.2017.f5-1.

\section{Results}

Creating a mouse model with Park2 knocked out in neurons with damaged mtDNA

PD-mito-PstI mice express a mitochondrial-targeted endonuclease (mito-PstI) under the indirect control of the DAT promoter. MitoPstI causes two sequence-specific double-strand breaks (DSBs) in the mtDNA of dopaminergic neurons (Pickrell et al., 2011a), leading to mtDNA depletion and, to a lesser extent, to the formation of recombinant mtDNA molecules (Srivastava and Moraes, 2005; Fukui and Moraes, 2009; Pickrell et al., 2011b). PD-mito-PstI mice show a clear and progressive parkinsonian phenotype with loss of $\mathrm{TH}^{+}$neurons, striatal DA depletion, and motor coordination defects (Pickrell et al., 2011a).

ParkinKO mice were generated by deleting exon 3 of PARK2 (Goldberg et al., 2003). They are viable and fertile without obvious abnormalities, have normal brain morphology, and have no significant alterations in their general behavior. The only disruption detected in the nigrostriatal system of ParkinKO mice is an elevated level $(20 \%)$ of extracellular DA in the striatum due to defective reuptake (Jiang et al., 2004; Oyama et al., 2010).

We crossed the PD-mito-PstI with ParkinKO animals to obtain ParkinKO-PD-mito-PstI. In the PD-mito-PstI and ParkinKO-PD-
mito-PstI mice, mito-PstI expression was continuously induced from birth. Both mouse models were born at expected Mendelian ratios and appeared normal at birth, apart from a small but significant decrease in body weight as previously reported (Kim et al., 2011). ParkinKO-PD-mito-PstI mice had reduced body weight, starting from 2 months of age and persisting until 12 months of age (Fig. 1A). The life span of PD-mito-PstI mice was not altered by the lack of Parkin up to 24 months.

\section{The lack of Parkin anticipates but does not worsen motor behavior in PD-mito-PstI mice}

We performed behavioral testing (Meredith and Kang, 2006) to determine whether the lack of Parkin combined with damaged mtDNA worsened the motor defects in the PD-mito-PstI mice. We used an ambulatory activity cage to measure spontaneous horizontal activity and exploration time for a period of $12 \mathrm{~h}$. At 2 months of age, we observed that ParkinKO-PD-mito-PstI mice moved significantly less in the cage compared with PD-mito-PstI mice (Fig. $1 B$ ), but this difference between the two groups was not significant at later time points $(4,8$, and $>12$ months of age; Fig. 1-1 available at https://doi.org/10.1523/JNEUROSCI.1384-17.2017. f1-1), suggesting that the loss of Parkin anticipates the onset but does not worsen the motor impairment in this model. When we tested 2-month-old mice for coordination (pole test, Rotarod) and with other motor tests (open field), we found that ParkinKOPD-mito-PstI mice had some degree of motor impairment compared with control mice (Fig. $1 D, F$ ), but we did not detect any difference when we compared them to PD-mito-PstI mice (Fig. 

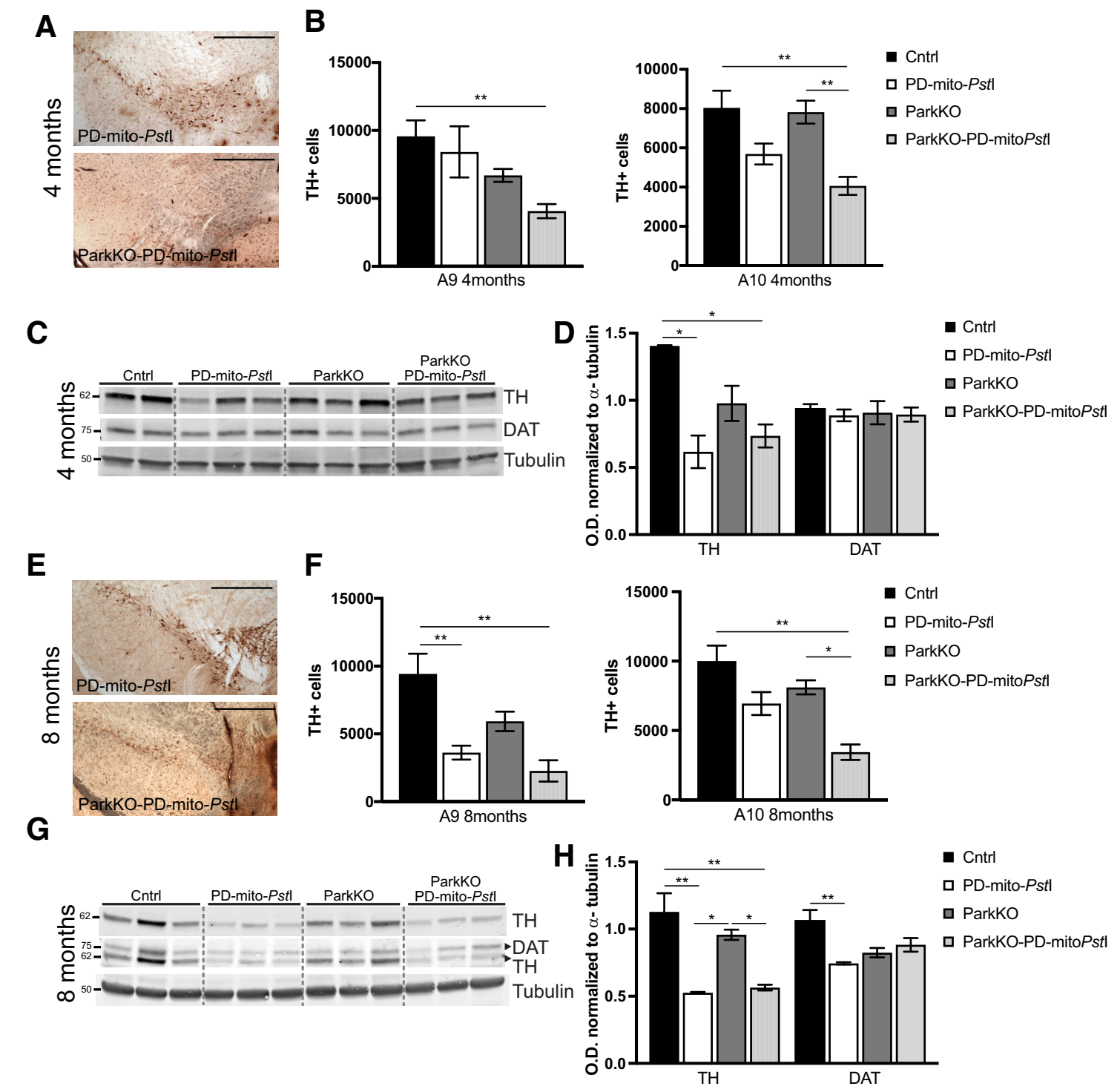

Figure 2. Degeneration of dopaminergic neurons in substantia nigra and loss of striatal axonal projections. $A, E$, Representative images of the midbrain sections immunostained to identify $\mathrm{TH}^{+}$ neurons for PD-mito-Pstl and ParkinK0-PD-mito-Pstl mice at $4(\boldsymbol{A})$ and $8(\boldsymbol{E})$ months of age. Scale bar, $500 \mu \mathrm{m}$. $\boldsymbol{B}, \boldsymbol{F}$, Graph representing the stereological quantification $\mathrm{A} 9$ and $\mathrm{A} 10 \mathrm{TH}{ }^{+}$cells $(n=$ 4-5/group) in 4-month-old $(\boldsymbol{B})$ and 8-month-old $(\boldsymbol{F})$ mice. $\boldsymbol{C}, \boldsymbol{D}$, Western blots showing levels of TH and DAT in 4-month-old mice striata $(\boldsymbol{C})$ and relative quantification $(\boldsymbol{D})$. $\boldsymbol{G}, \boldsymbol{H}$, Western blots showing levels of TH and DAT in 8-month-old mice striata $(G)$ and relative quantification $(\boldsymbol{H})$. Molecular weights are indicated on the left of the gels. Error bars \pm SEM. $n=5 /$ group. ${ }^{*} p<0.05$ $* * 0<0.01$.

$1 C-F)$, indicating that the lack of Parkin did not worsen the motor phenotype already present in the PD-mito-PstI mice at 2 months of age. We tested the mice for the same motor skills at later time points $(4,8$, and $>12$ months of age), but we did not detect any significant difference between PD-mito-Pst I mice with or without the expression of Parkin (Fig. 1-1 available at https://doi.org/10.1523/JNEUROSCI.1384-17.2017.f1-1).

\section{Loss of endogenous Parkin anticipates neuropathological signs in PD-mito-PstI mice}

We previously reported that the earliest time point when we observed a significant loss of $\mathrm{TH}^{+}$cells in the $\mathrm{SN}$ of PD-mito-Pst mice was 8 months (Pickrell et al., 2011a; Fig. 2E,F). We tested whether the absence of Parkin worsened the dopaminergic neurodegeneration present in the $\mathrm{PD}$-mito-Pst I mice. We found that $\mathrm{TH}^{+}$neurons were decreased in the SN (A9) of the ParkinKOPD-mito-Pst I mice already at 4 months of age (Fig. $2 A, B ; p=$ 0.009). We noticed that ParkinKO-PD-mito-PstI mice showed a decreased number of $\mathrm{TH}^{+}$neurons also in the VTA (A10) at 4 months (Fig. $2 A, B ; p=0.0026$ ) and at 8 months (Fig. $2 E, F ; p=$ $0.0016)$. These data suggest that the lack of Parkin exacerbated the neurodegenerative process.

The SN neurons project their axons to the striatum. The degeneration of these dopaminergic axons and the consequent depletion of dopamine in the striatum is the cause of the motor impairments in PD. We previously showed that in PD-mito-PstI mice the striatal content of TH and DAT (indicative of the presence of dopaminergic axons) was reduced already at 4 months, before the degeneration of the cell body in the substantia nigra (Pickrell et al., 2011a). We performed immunostaining and Western blot assays using anti-TH and anti-DAT antibodies in the ParkinKO-PD-mito-PstI mice, and, although TH levels were reduced in the striatum at both 4 months (Fig. $2 D ; p=0.021$ ) and 8 months (Fig. $2 H ; p=0.0028$ ), we did not detect significant changes compared with the PD-mito-PstI mice. The absence of Parkin also did not affect the levels of DAT in the striatum (Fig. 2C,D, G,H). 

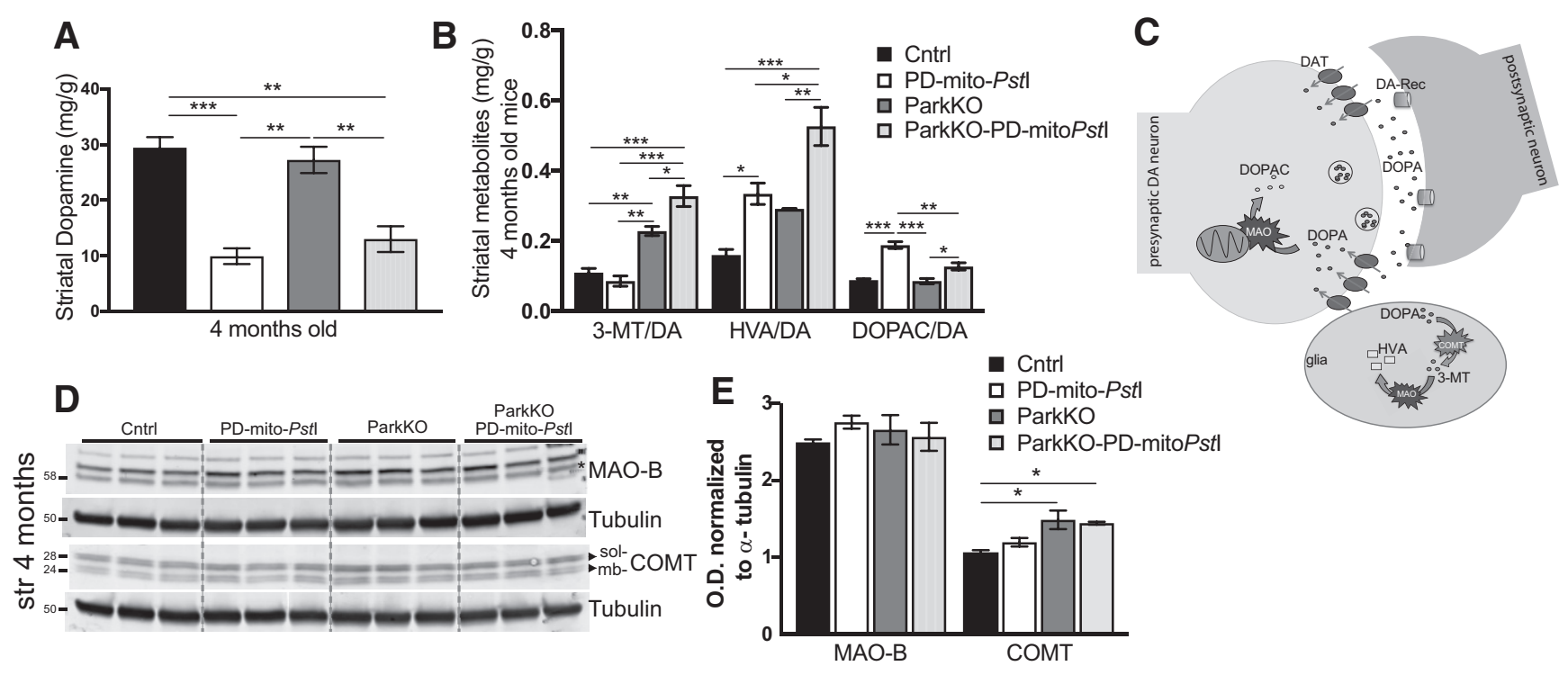

Figure 3. Striatal alterations of dopamine and its metabolites. $A$, Quantification of DA normalized for milligrams of proteins in striata of 4-month-old animals ( $n=3-5 / \mathrm{group})$. $\boldsymbol{B}$, Quantification of degradation metabolites normalized for dopamine content (3-MT/DA, HVA/DA, and DOPAC/DA) in striata of 4-month-old animals ( $n=3-5 /$ group). C, Representation of a dopaminergic synapses and cartooned scheme of enzymes involved in the degradation of dopamine. $\boldsymbol{D}, \boldsymbol{E}$, Western blots showing levels of MAO-B and COMT protein in striata of 4-month-old mice $(\boldsymbol{D})$ and relative quantification (E). Soluble (sol) and membrane bound (mb) are two forms of COMT. Molecular weights are indicated on the left of the gels. ${ }^{*} p<0.05,{ }^{* *} p<0.01,{ }^{* * *} p<0.001$. Figure $3-1$ available at https://doi.org/10.1523/JNEUROSCI.1384-17.2017.f3-1 describes the same dopaminergic metabolites analyses in older mice. Figure 3-2 available at https://doi.org/10.1523/JNEUROSCI. 1384-17.2017.f3-2 describes detailed statistical analyses.

We then quantified the amount of dopamine and its downstream metabolites dihydroxyphenylacetic acid (DOPAC), 3-methoxytyramine (3-MT), and homovanillic acid (HVA) in freshly isolated striatum samples from animals of different ages. Although DA levels were markedly reduced in ParkinKO-PDmito-PstI mice compared with control animals already at 4 months of age (Fig. $3 \mathrm{~A}$ ), the absence of Parkin had no effect at 4 , 8, or 12 months of age (Fig. $3 A$ and Fig. 3-1 available at https:// doi.org/10.1523/JNEUROSCI.1384-17.2017.f3-1), which is consistent with our finding that there are similar amounts of innervating fibers in these mice. However, we noticed higher levels of 3-MT and HVA both in the absolute quantification and after normalization for dopamine levels (Fig. $3 B ; p<0.0001$ ) in ParkinKOPD-mito-PstI compared with PD-mito-PstI mice. This increase in dopamine metabolites despite equal amounts of striatal DA suggests that the loss of Parkin affects the turnover rate of DA in the surviving $\mathrm{TH}^{+}$neurons.

Monoamine oxidase (MAO) and catechol $O$-methyltransferase (COMT) are the two main enzymes involved in the turnover of DA (Fig. 3C). After the release in the synaptic cleft, the extracellular DA has to be removed, and it is either recycled after reuptake by dopaminergic neurons or degraded after uptake by glial cells (Vaughan and Foster, 2013). In the dopaminergic neurons, DA is degraded to DOPAC by MAO. In the glial cells, DA is degraded by MAO and also by COMT to HVA (Meiser et al., 2013). To analyze whether the increase of DA metabolites in the striata of ParkinKO mice was due to increased activity of these enzymes, we performed a Western blot probing for anti-MAO-B and antiCOMT. We did find a small but significant increase in the concentration of COMT in the striatum of 4 months old ParkinKO and ParkinKO-PD-mito-PstI mice (Fig. $3 D, E ; p=$ 0.019 ) that could explain the accelerated metabolism of DA in the absence of Parkin. COMT is prevalently expressed by glial cells (Myöhänen et al., 2010). Since in our mice Parkin is knocked out ubiquitously, we believe that this effect is due to the lack of Parkin in striatal glial cells. At later time points (8 and 12 months), we also found an increase in MAO-B (Fig. 2-1 E, F available at https://doi.org/10.1523/JNEUROSCI.1384-17.2017.f2-1).

\section{MtDNA levels are increased in mice lacking endogenous Parkin}

Parkin was shown to participate in the clearance of mitochondria with damaged mtDNA in cultured cells (Suen et al., 2010). MitoPstI promotes DSB in two mtDNA sites, causing mainly mtDNA depletion and, to a smaller extent, the generation of recombined mtDNA. To analyze how the absence of Parkin affects mitochondria with damaged mtDNA, we measured the levels of different types of mtDNA alterations (depletion, deletions, and oxidative lesions) in ParkinKO-PD-mito-PstI mice and relative controls.

To measure relative mtDNA levels in the cell bodies of dopaminergic neurons, we isolated $\mathrm{TH}^{+}$cells by laser capture microdissection (LCM) after staining consecutive midbrain slices. We extracted the DNA from the collected cells and measured the mtDNA copy number using quantitative real-time qPCR. To determine the relative levels of total mtDNA in each sample, we used a primer set that amplifies an mtDNA region between one of the PstI sites and the D-loop (Pickrell et al., 2011a; Fig. 4A, COXI region). As expected, mtDNA levels were reduced in the PDmito-PstI mice compared with controls, but we detected higher levels of total mtDNA in ParkinKO-PD-mito-PstI mice compared with PD-mito-PstI mice (Fig. 4B). Likewise, ParkinKO $\mathrm{TH}^{+}$neurons also had more mtDNA than in wild-type mice (Fig. $4 B)$.

The axons of dopaminergic neurons project to the striatum. By using $\mathrm{qPCR}$ and Southern blot analysis, we assessed the mtDNA levels in striatal homogenates. It is important to note that, while we used LCM for dissecting dopaminergic cell bodies, we used homogenized striatal tissue for the analysis of the axons. The manually isolated striatal region is enriched in dopaminergic terminals but also contains different cell populations and different neuronal terminals. Also in striata homogenates, higher levels of total mtDNA were detected in ParkinKO-PD-mito-PstI mice 
A

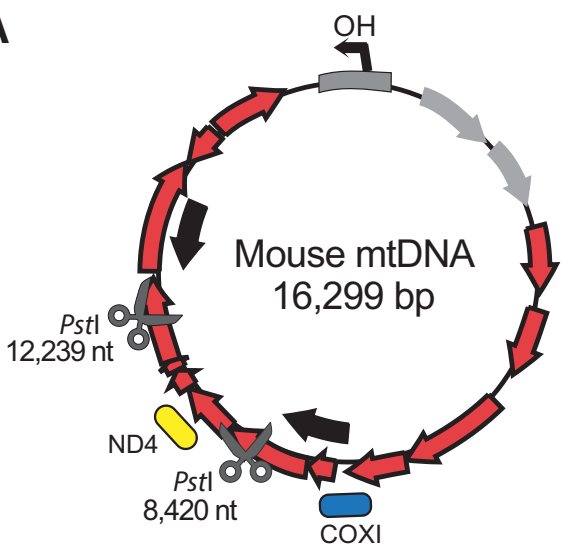

C

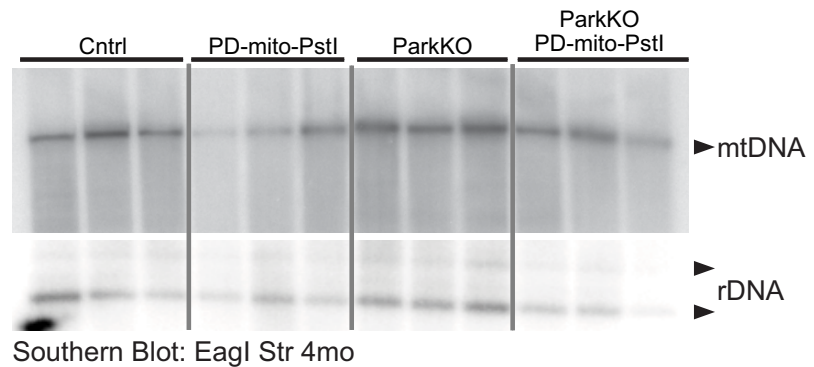

E Full-length mtDNA Striatum

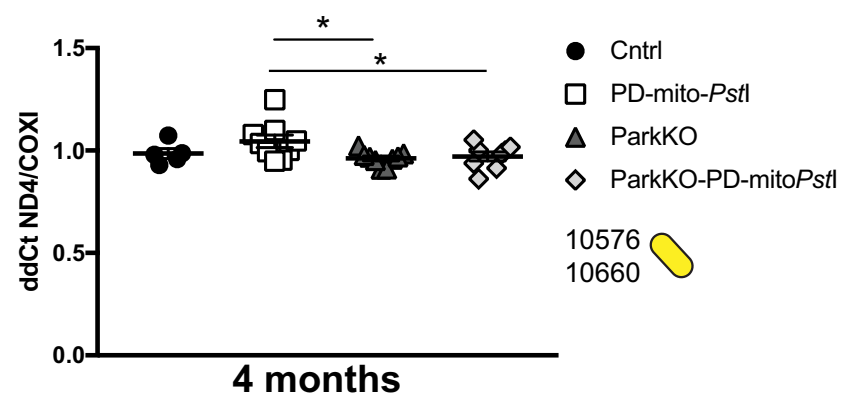

B

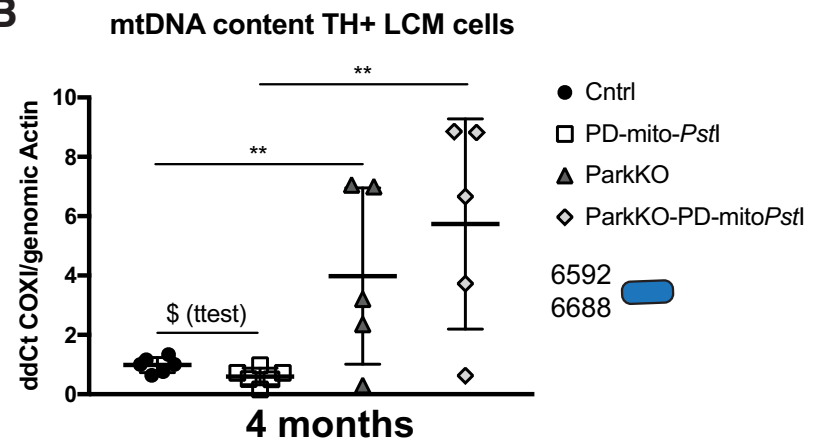

mtDNA content Striatum

D

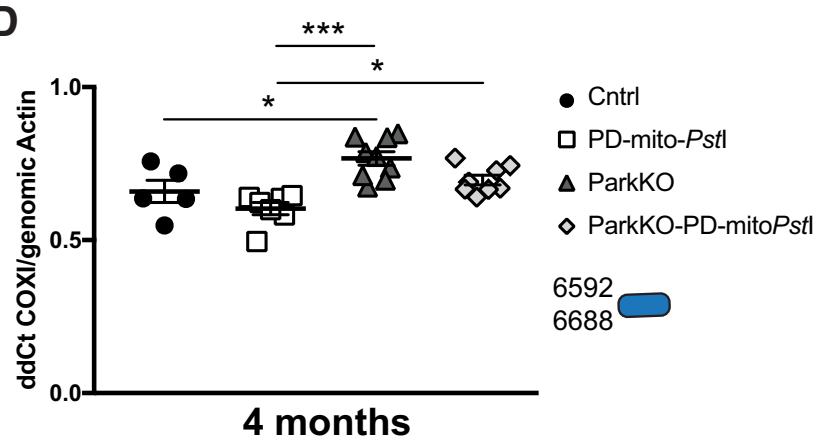

$\mathbf{F}$

Recombinant mtDNA Striatum

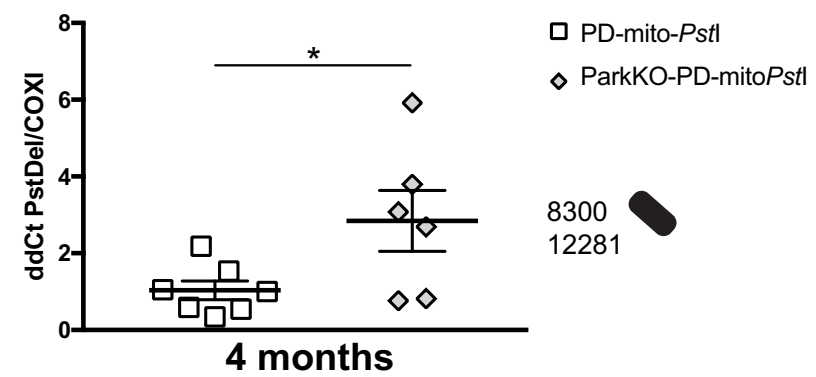

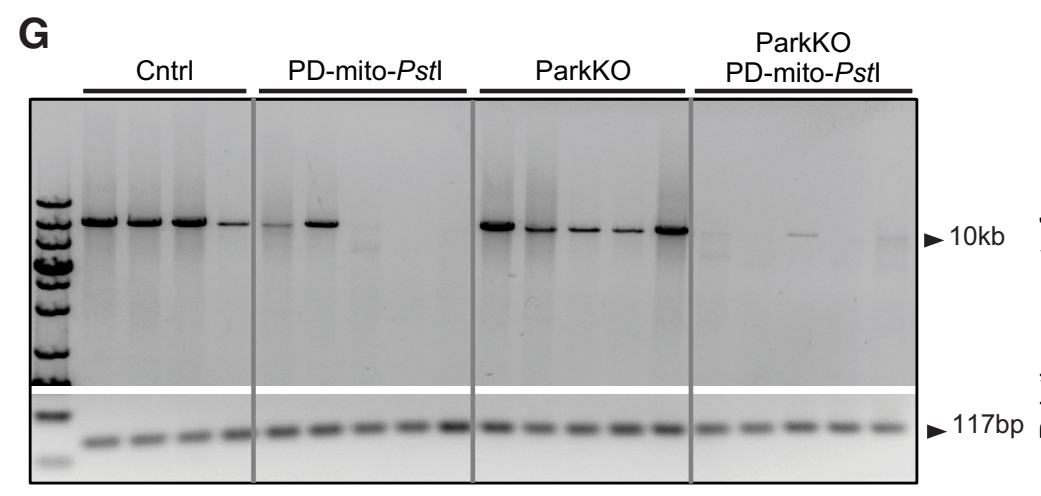

H Long-range PCR

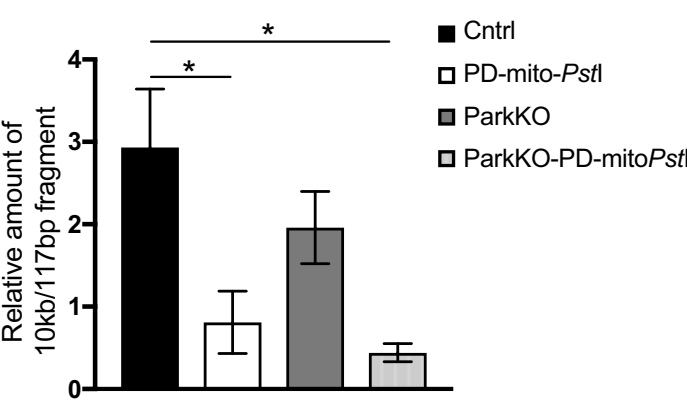

Figure 4. mtDNA deletions and mutations increase when endogenous Parkin is lost in striata of PD-mito-Pstl mice. $A$, Schematic representation of mouse mtDNA. Scissors indicate the Pstl cleavage sites. Red arrows represent encoded proteins. Gray arrows represent mt-tRNAs. Color-coded representation of the position of the amplicons used for the qPCRs is maintained in the graphs. $\boldsymbol{B}$, mtDNA levels measured by qPCR of LCM-collected SN TH ${ }^{+}$neurons $(n=5 /$ group; $T=p$ value after $t$ test). $\boldsymbol{C}, \boldsymbol{D}$, Southern blot probing striatal DNA with $\mathrm{mtDNA}$ and nuclear DNA probes $(\boldsymbol{C})$ and mtDNA content measured by $\mathrm{PPCR}(\boldsymbol{D})$ in 4-month-old animals. $\boldsymbol{E}$, Quantification by $\mathrm{PPCR}$ of full-length mtDNA content in striata of 4-month-old animals. $\boldsymbol{F}$, Recombination events detected by $q P C R$ using primers flanking the Pstl sites in striatal samples. $\boldsymbol{G}, \boldsymbol{H}$, Long-range PCR amplification of a $10 \mathrm{~kb}$ and a $117 \mathrm{bp}$ fragment from striatal DNA $(\boldsymbol{G})$ and relative quantification of a $10 \mathrm{~kb}$ fragment normalized to the 117 bp fragment $(\boldsymbol{H})$. Boxes in graphs $\boldsymbol{B}, \boldsymbol{D}$, and $\boldsymbol{F}$ represent one individual animal. ${ }^{*} p<0.05,{ }^{* *} p<0.01,{ }^{* * *} p<0.001$. Figure $4-1$ available at https://doi.org/10.1523/ JNEUROSCI.1384-17.2017.f4-1 describes mtDNA levels in older mice and different brain regions. Figure 4-2 available at https://doi.org/10.1523/JNEUROSCI.1384-17.2017.f4-2 and Figure 4-3 available at https://doi.org/10.1523/JNEUROSCI.1384-17.2017.f4-3 describe detailed statistical analyses. 
compared with PD-mito-PstI mice (Fig. 4C,D). After being cleaved by mito-PstI, mtDNA undergoes depletion and, albeit at low levels, recombination between the two PstI sites (Pickrell et al., 2011a). Because Parkin is supposed to target damaged mitochondria to mitophagy, we expected mice lacking Parkin to accumulate defective mitochondria with deleted mtDNA molecules. We designed primers flanking the PstI sites to specifically amplify the breakpoint region (Fig. $4 A$, arrows). A qPCR of DNA from striata of the different groups of mice showed higher levels of recombinant mtDNA in the ParkinKO-PD-mito-Pst I mice compared with PD-mito-PstI mice (Fig. 4F) and lower levels of full-length mtDNA (Fig. 4E).

To analyze whether the mtDNA in ParkinKO-PD-mito-PstI striata mice accumulated oxidative damage, we performed a previously characterized quantitative long-range PCR approach (see Materials and Methods). This assay is based on the observation that different types of damage (e.g., single-strand breaks, oxidative modifications, abasic sites, and bulky adducts) slow down or halt TaqDNA polymerase progression, resulting in reduced amplification yield (Santos et al., 2006; Maslov et al., 2013). We used two pairs of primers in separate reactions, one amplifying a $10 \mathrm{~kb}$ fragment, which is susceptible to impaired amplification, and a second, which amplifies a $117 \mathrm{bp}$ internal control fragment, not expected to be significantly affected by these modifications. (Furda et al., 2012). When we analyzed mtDNA from striata of 4-month-old mice, we found that mtDNA from PD-mito-Pst and ParkinKO-PD-mito-PstI mice showed reduced amplifications when compared with controls, indicating increased mtDNA damage associated with the presence of mito-PstI. There were no significant changes between PD-mito-PstI and ParkinKO-PD-mito-PstI mice, suggesting either that the accumulation of base modifications is not exacerbated by the absence of Parkin or that the method is not sensitive enough to differentiate already markedly impaired amplifications (Fig. 4G,H).

We performed the same analysis in the mtDNA at later time points (12 and 19 months) by analyzing both striatum and dissected midbrain, but we did not detect any changes in the mtDNA, probably because of the depletion of dopaminergic axons and neurons at these ages (Fig. 4-1 available at https://doi. org/10.1523/JNEUROSCI.1384-17.2017.f4-1).

\section{Mito-PstI and lack of Parkin did not lead to A10 cortical axon degeneration}

As part of the meso-cortico-limbic pathway, part of VTA dopaminergic neurons project their axons to the cortex, specifically to the prefrontal and cingulate cortex. In PD, the VTA neurons (A10) are relatively spared. In our PD-mito-PstI mice, we did not detect a depletion of A10 neurons, while in ParkinKO-PD-mitoPstI mice there is already a $50 \%$ decrease of A10 cells early in the course of the disease (Fig. $2 B$ ). To investigate whether the degenerating cells were the ones projecting to the cortex, we analyzed cortices in 12-month-old animals. The content of cortical TH was much lower compared with striatal $\mathrm{TH}$, but the expression of mito-Pst I did not cause any further TH depletion in this region (Fig. 5A). We then analyzed the mtDNA depletion and recombination by Southern blot and found an accumulation of recombinant mtDNA molecules in cortices of 12-month-old animals (Fig. $5 B, C, G$ ). The mtDNA accumulation was not accompanied by an increase in Porin, indicating that also in this region, mitochondrial mass was not affected.

Full-length mtDNA was slightly decreased in cortex of mitoPstI-expressing mice. The absence of Parkin resulted in even higher levels of deleted mtDNA (Fig. $5 E-G$ ). It is interesting to note that mito-PstI-generated deletions are usually present at very low levels, detectable only by qPCR. However, in this case the deleted mtDNA was clearly detected by Southern blot.

\section{Lack of Parkin modified mitochondrial morphology but not total mitochondrial mass}

The fact that the recombinant mtDNA was increased in the mice lacking Parkin is compatible with the suggested role of Parkin in the clearance of mitochondria with damaged mtDNA by mitophagy. To study the state of mitochondria and the activation of mitophagy in our mice, we analyzed mitochondrial and mitophagy markers.

Porin, Tim23, and several OXPHOS proteins (ATP5a, UQRC2, mtCO1, SDHB, and NDUFB8) were not changed in 4-month-old mice lacking Parkin (Fig. 6A), suggesting that mitochondrial mass was not altered by the lack of Parkin. Likewise, we did not observe a change in the levels of PARIS, a repressor of PGC- $1 \alpha$ (Fig. 6A). When we measured p62 and LC3b (autophagy markers), we also did not detect significant changes (Fig. 6B). We performed the same quantification in older mice (12 months old) obtaining the same results (Fig. 4-1 I, J available at https://doi.org/10.1523/JNEUROSCI.1384-17.2017.f4-1).

Because mtDNA was increased but total mitochondrial mass was not, we analyzed mitochondrial morphology of mice lacking Parkin and controls. To do so, we crossed our mice with TREmito-eYFP mice that express eYFP targeted to the mitochondria (Chandrasekaran et al., 2006). Using Fiji software (see Materials and Methods), we were able to quantify axonal mitochondria in dopaminergic neurons and separate them into four groups depending on their size. We analyzed midbrain slices from 4-month-old animals, and we observed a small but significant decrease in mitochondrial number only in the dopaminergic axons of ParkinKO-PD-mito-Pst $\mathrm{I}^{\text {mito-eYFP }}$ mice (Fig. $6 C$ ). When we analyzed mitochondrial size, we observed that the lack of Parkin led to the accumulation of larger mitochondria (Fig. 6D,E). We also examined the steady-state levels of the following two proteins associated with mitochondrial dynamics: Mfn2 and OPA1, which is involved in the fusion of the outer and the inner mitochondrial membrane, respectively. Although we did not detect changes in Mfn2 levels, there was a slight decrease in OPA1 (long form) levels in striatal homogenates from 4- and 12-month-old animals (Fig. $6 B$ and Fig. 4-1 J available at https://doi.org/10. 1523/JNEUROSCI.1384-17.2017.f4-1).

\section{Discussion}

Park2 is one of the confirmed genes mutated in monogenic forms of Parkinson's disease, but the loss of Parkin does not severely affect the nigrostriatal pathway in mice (Goldberg et al., 2003; Von Coelln et al., 2004; Perez and Palmiter, 2005). A few possible explanations have been proposed for this observation. Mitochondrial defects accumulate with aging and play a role in the pathology of PD. It is possible that mitochondrial dysfunctions in mice do not reach thresholds high enough for the loss of Parkin to have any detrimental effect (LaFrance et al., 2005), but this hypothesis is conflicting with the clearly severe effects that Parkin loss has in even more short-lived organisms such as zebrafish and Drosophila (Hattori et al., 1998; Greene et al., 2003; Flinn et al., 2009). Another hypothesis is that other pathways such as unselective macroautophagy or the recently described Rheb mitophagic pathway, which controls basal levels of mitochondria in normal conditions, compensate for the loss of Parkin (Hara et al., 2006; Melser et al., 2013). Finally, knocking out Parkin in the mouse germline could also induce compensatory mechanisms, and the fact that deleting the Parkin gene after development does cause dopami- 

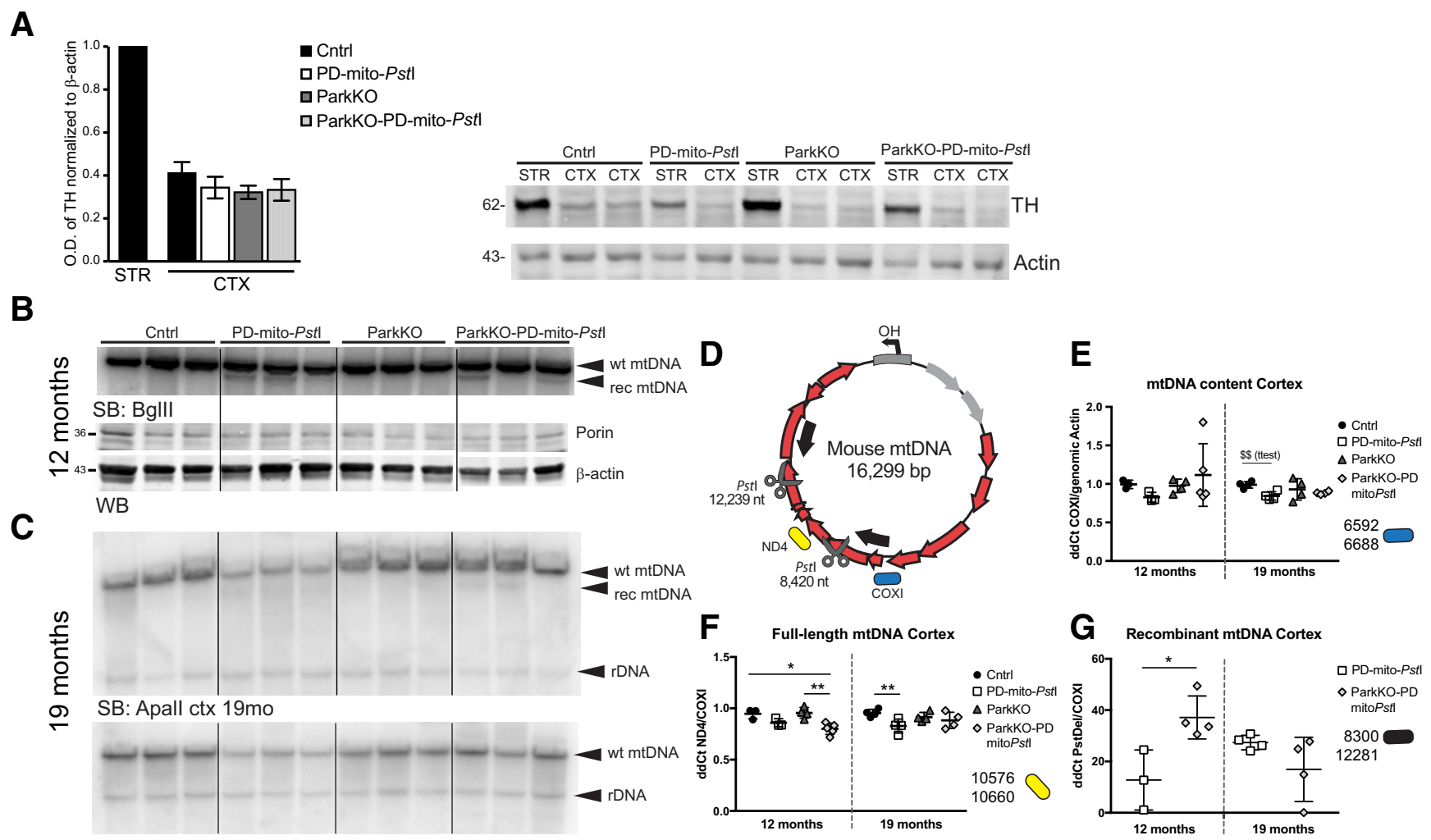

Figure 5. Alterations of dopaminergic terminals and mtDNA in cortical region of ParkKO-PD-mitoPstl mice. $A$, Quantification of cortical TH in 12 -month-old animals and representative Western blot. CTX, cortex; STR, striatum. B, Southern blot probing cortical DNA with mtDNA and nuclear DNA (nDNA) probes and relative Western blot probing for Porin in 12-month-0ld animals. Molecular weights are indicated on the left of the gels. C, Southern blot probing cortical DNA with mtDNA and nDNA probes in 19-month-old animals. D, Schematic representation of mouse mtDNA and qPCR analysis of mtDNA in cortices of 12- and 19-month-old mice. Color-coded representation of the position of the amplicons used for the qPCRs is maintained in the graphs. $\boldsymbol{E}$, Total mtDNA levels measured by qPCR of cortex from 12- and 19-month-old animals. $F$, Quantification by qPCR of full-length mtDNA content in cortices of 12-and 19-month-old animals. $G$, Recombination events detected by $\mathrm{PPCR}$ using primers flanking the Pstl sites in cortical samples from 12 - and 19 -month-old animals. ${ }^{*} p<0.05,{ }^{* *} p<0.01$. Figure 5 -1 available at https://doi.org/10.1523/JNEUROSCI. 1384-17.2017.f5-1 describes detailed statistical analyses.

nergic neurodegeneration corroborates this hypothesis (Shin et al., 2011; Stevens et al., 2015).

Other groups have crossed mouse models of mitochondrial dysfunction with the ParkinKO mouse and, depending on the type of mitochondrial insult, different results have been reported. In TFAM KO-ParkinKO mice, where TFAM is specifically knocked out in dopaminergic neurons, there was no worsening of dopaminergic neurodegeneration (Sterky et al., 2011). In this case, it has been proposed that the rapid depletion of mtDNA and neurodegeneration may not allow enough time for it to be partially compensated by endogenous Parkin. In addition, there are reports that the loss of Parkin did not worsen motor phenotypes in two mouse models affecting mitochondrial fission and fusion [Purkinje cell-specific dynamin-related protein 1 (Drp-1) KO mice; Lee et al., 2012] and dopaminergic neuron-specific Mfn2 KO mice (Kageyama et al., 2012; Lee et al., 2012). However, it has been shown that the loss of Drp-1 or Mfn2 in a cell culture does not cause sufficient mitochondrial dysfunction to recruit Parkin (Narendra et al., 2008; Tanaka et al., 2010). On the other hand, two recent publications showed that the lack of Parkin exacerbates neurodegeneration in two mouse models of PD obtained by increasing mtDNA mutations. In the Mutator mouse, the lack of Parkin combined with the accumulation of mtDNA mutations was associated with neurodegeneration, striatal DA depletion and parkinsonian-like phenotypes, which were absent in the $\mathrm{Mu}$ tator mouse alone (Pickrell et al., 2015). In the Twinkle-TG mouse, in which mtDNA deletions are increased specifically in substantia nigra, the absence of Parkin led to higher mtDNA deletion levels, lower mitochondrial function and membrane potential, and severe neurobehavioral deficits at 19 months (Song et al., 2017).

Our results showed that the lack of Parkin mildly accelerated, but overall did not worsen, the motor defects and the dopaminergic neurodegeneration present in the PD-mito-PstI mice. A curious observation was the fact that dopamine metabolism was affected by the lack of Parkin: we detected an increase in COMT and later an increase in MAO, enzymes involved in the metabolism of dopamine. Parkin overexpression was shown to reduce MAO expression in cultured cells (Jiang et al., 2006). Because COMT is present mostly in glial cells, we suggest that the COMT increase was due to the lack of Parkin in the glial cells rather than in the dopaminergic striatal axons.

Another novel observation obtained from our analysis is that the lack of Parkin resulted in an increase of mtDNA levels in midbrain (Fig. 4-1 B, homogenates, available at https://doi.org/ 10.1523/JNEUROSCI.1384-17.2017.f4-1 and Fig. 4B, LCM microdissected neurons) and striata (Fig. $4 D$ ) of 4-month-old mice. These changes were not observed at later time points, likely because of neuronal (and axonal) loss.

Recent work showed that the loss-of-function mutations in Parkin and PINK1 in Drosophila lead to the accumulation of dysfunctional mitochondria due to defective mitophagy halting mitochondrial protein turnover (Burman et al., 2012; Vincow et al., 2013). Despite our results being compatible with the previ- 

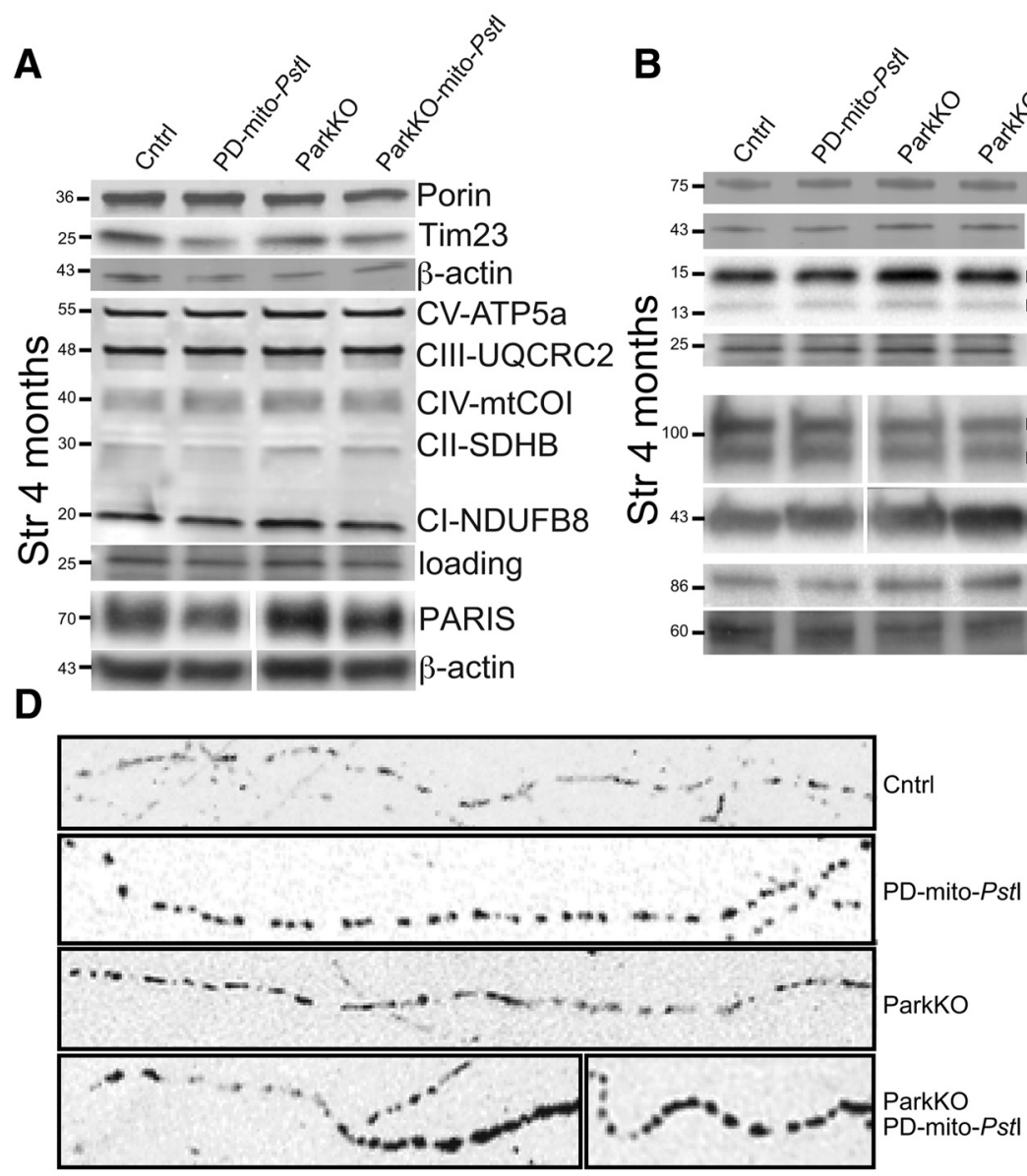
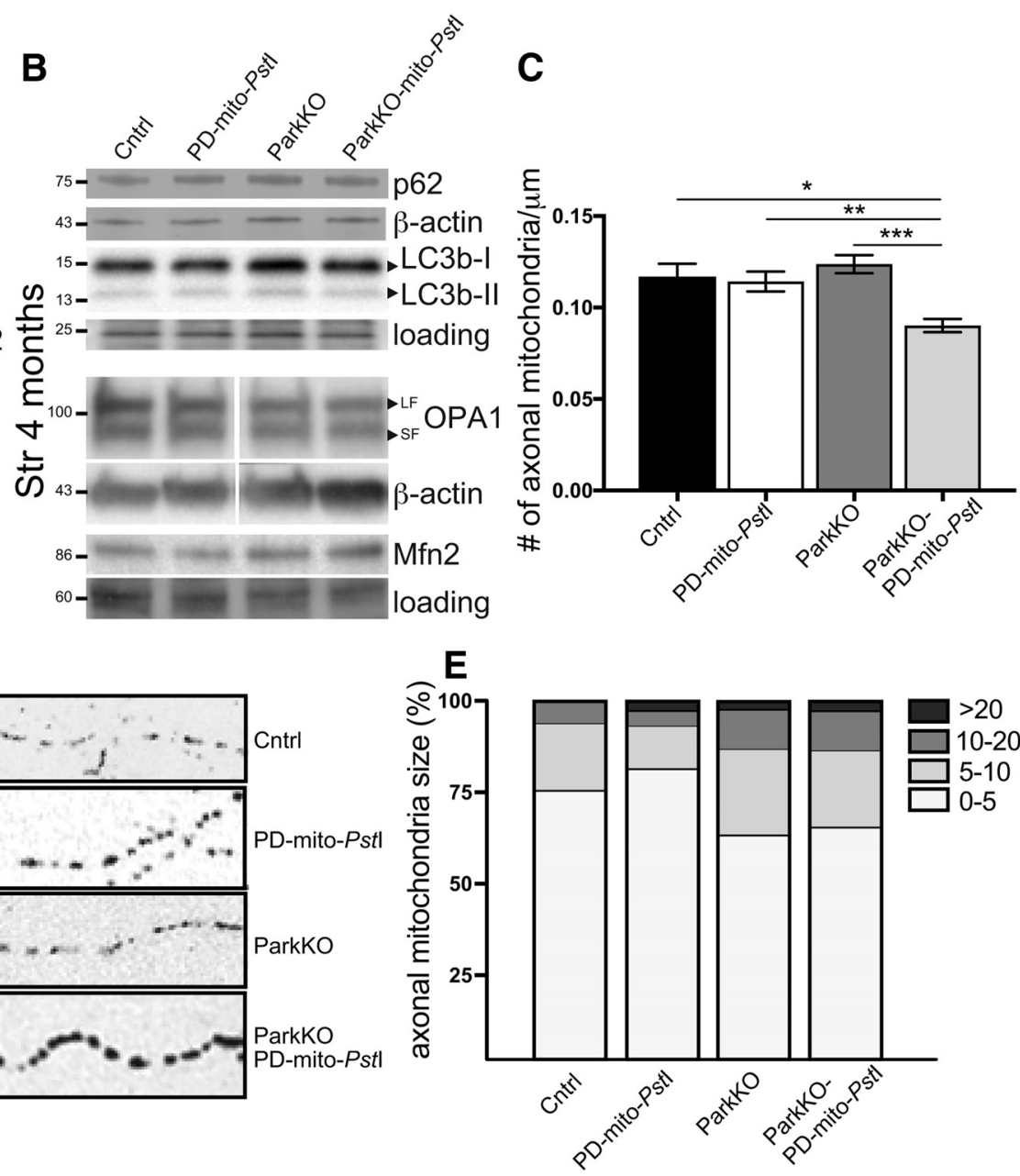

Figure 6. Mitochondrial morphology in striatal and nigral dopaminergic axons. $\boldsymbol{A}$, Representative Western blots probing for mitochondrial markers Porin, Tim23, OXPHOS cocktail proteins, and PARIS in striata of 4-month-old animals. Actin was used as a housekeeping gene for normalization ( $n=3-4 / g r o u p)$. $B$, Representative Western blots probing for autophagy markers $p 62$ and $L$ C $3 \mathrm{~b}$ in striata of 4-month-old animals. Actin and tubulin were used as housekeeping genes for normalization ( $n=3-4 /$ group). Molecular weights are indicated on the left of the gels. $C$, Quantification of the mitochondrial total number in dopaminergic cell axons, normalized for axon length. $\boldsymbol{D}$, Representative black and white images of axonal mitochondria in mice expressing mito-eYFP. $\boldsymbol{E}$, Quantification of axonal mitochondria divided by size. ${ }^{*} p<0.05,{ }^{* *} p<0.01,{ }^{* * *} p<0.001$.

ously suggested mechanistic mitophagy model, it is important to analyze them without a preconceived notion. In fact, although the levels of mtDNA were increased, we could not detect a corresponding increase in mitochondrial proteins in striatal samples, and markers of mitophagy (LC3b and p62) were also unchanged.

Interestingly, when we analyzed axonal mitochondrial number and morphology in the midbrain of ParkinKO-PD-mito-PstI mice, we observed a clear shift from small-sized to enlarged organelles. The number of total mitochondria was decreased. This would suggest that the fusion/fission process in defective mitochondria is affected by the absence of Parkin. This phenomenon could be explained by the fact that, in pathological conditions, Parkin inhibits the fusion of defective mitochondrial by the ubiquitination of Mfn2 (Poole et al., 2010; Ziviani et al., 2010). When we analyzed Mfn2 levels in our mice, though, we detected no changes. We also analyzed the levels of OPA1, which is involved in the mitochondrial inner membrane fusion, and again we detected no change (in midbrain; data not shown) or only a mild decrease (in striatal samples; Fig. 6B,E,F and Fig. 4-1 J available at https://doi.org/10.1523/JNEUROSCI.1384-17.2017.f4-1).

Another possible explanation for the accumulation of mtDNA without an increase in mitochondria biogenesis, is that a mtDNA pool is increased in the striatum of ParkinKO mice. Parkin has not been shown to interact with the mtDNA replicative processes, but the full repertoire of Parkin ubiquitination substrates is still being defined. Rothfuss et al. (2009) showed that Parkin can associate with mtDNA and protect it against oxidative stress. Sarraf et al. (2013) showed how the Parkin-dependent ubiquitylome includes not only proteins of the mitochondrial outer membrane but also proteins expressed in the mitochondrial matrix, such as the mtDNA single-strand binding protein 1 (SSBP1), implying the possibility that Parkin could have a role in the mtDNA maintenance. In fact, the increased levels of deleted mtDNA could be due to increased replication, which could favor smaller molecules (Diaz et al., 2002).

Mitochondrial morphology, which was impaired in our mice, is intrinsically associated with mtDNA replication: lack of mitofusins leads to a severe mtDNA depletion (Chen et al., 2010), and OPA1 appears to regulate mtDNA copy number (Elachouri et al., 2011). Moreover, Parkin seems to regulate OPA1 through NEMO (nuclear factor- $\kappa \mathrm{B}$ essential modulator; Müller-Rischart et al., 2013), and a recent study reported the occurrence of syndromic parkinsonism with an OPA1-dominant mutation associated with accumulation of mtDNA deletions (Carelli et al., 2015). In our model, however, the increase in mtDNA was not accompanied by 
an increase in OPA1; therefore, we could not confirm this effect in our system.

Finally, the observed increase in mtDNA levels in our mice may not be a direct consequence of the lack of Parkin but a compensatory protective mechanism of dopaminergic neurons to partially rescue the nigrostriatal integrity (Perier et al., 2013). Accordingly, it was recently described that mtDNA content is increased in dopaminergic neurons of aged healthy individuals, suggesting the presence of a mechanism to maintain the pool of wild-type mtDNA population despite accumulating deletions. This process appears to fail in PD, resulting in the loss of wildtype mtDNA, suggesting that the dysregulation of mtDNA homeostasis is a key process in the pathogenesis of neuronal loss in Parkinson disease (Dölle et al., 2016).

In conclusion, we showed that the absence of Parkin, in a mouse model where mtDNA undergoes double-strand breaks and recombination in dopaminergic cells, does not lead to a worsening of the PD phenotype. However, lack of Parkin was associated with an increase in both wild-type and recombinant mtDNA. The simplest explanation for these observations would be that mitochondrial dynamics was altered, impairing mitophagy and mtDNA degradation. However, because markers of mitophagy were not changed, our observations suggest that Parkin has a role (direct or indirect) in mtDNA turnover or maintenance.

\section{References}

Bender A, Krishnan KJ, Morris CM, Taylor GA, Reeve AK, Perry RH, Jaros E, Hersheson JS, Betts J, Klopstock T, Taylor RW, Turnbull DM (2006) High levels of mitochondrial DNA deletions in substantia nigra neurons in aging and Parkinson disease. Nat Genet 38:515-517. CrossRef Medline

Braak H, Ghebremedhin E, Rüb U, Bratzke H, Del Tredici K (2004) Stages in the development of Parkinson's disease-related pathology. Cell Tissue Res 318:121-134. CrossRef Medline

Bratic A, Larsson NG (2013) The role of mitochondria in aging. J Clin Invest 123:951-957. CrossRef Medline

Burman JL, Yu S, Poole AC, Decal RB, Pallanck L (2012) Analysis of neural subtypes reveals selective mitochondrial dysfunction in dopaminergic neurons from parkin mutants. Proc Natl Acad Sci U S A 109:10438-10443. CrossRef Medline

Cagniard B, Beeler JA, Britt JP, McGehee DS, Marinelli M, Zhuang X (2006) Dopamine scales performance in the absence of new learning. Neuron 51:541-547. CrossRef Medline

Carelli V, Musumeci O, Caporali L, Zanna C, La Morgia C, Del Dotto V, Porcelli AM, Rugolo M, Valentino ML, Iommarini L, Maresca A, Barboni P, Carbonelli M, Trombetta C, Valente EM, Patergnani S, Giorgi C, Pinton P, Rizzo G, Tonon C, et al (2015) Syndromic parkinsonism and dementia associated with OPA1 missense mutations. Ann Neurol 78:2138. CrossRef Medline

Chandrasekaran K, Hazelton JL, Wang Y, Fiskum G, Kristian T (2006) Neuron-specific conditional expression of a mitochondrially targeted fluorescent protein in mice. J Neurosci 26:13123-13127. CrossRef Medline

Chen H, Vermulst M, Wang YE, Chomyn A, Prolla TA, McCaffery JM, Chan DC (2010) Mitochondrial fusion is required for mtDNA stability in skeletal muscle and tolerance of mtDNA mutations. Cell 141:280-289. CrossRef Medline

Damiano M, Gautier CA, Bulteau AL, Ferrando-Miguel R, Gouarne C, Paoli MG, Pruss R, Auchère F, L'Hermitte-Stead C, Bouillaud F, Brice A, Corti O, Lombès A (2014) Tissue- and cell-specific mitochondrial defect in Parkin-deficient mice. PLoS One 9:e99898. CrossRef Medline

Dauer W, Przedborski S (2003) Parkinson's disease: mechanisms and models. Neuron 39:889-909. CrossRef Medline

Diaz F, Bayona-Bafaluy MP, Rana M, Mora M, Hao H, Moraes CT (2002) Human mitochondrial DNA with large deletions repopulates organelles faster than full-length genomes under relaxed copy number control. Nucleic Acids Res 30:4626-4633. CrossRef Medline

Dölle C, Flønes I, Nido GS, Miletic H, Osuagwu N, Kristoffersen S, Lilleng PK, Larsen JP, Tysnes OB, Haugarvoll K, Bindoff LA, Tzoulis C (2016) Defective mitochondrial DNA homeostasis in the substantia nigra in Parkinson disease. Nat Commun 7:13548. CrossRef Medline
Elachouri G, Vidoni S, Zanna C, Pattyn A, Boukhaddaoui H, Gaget K, Yu-Wai-Man P, Gasparre G, Sarzi E, Delettre C, Olichon A, Loiseau D, Reynier P, Chinnery PF, Rotig A, Carelli V, Hamel CP, Rugolo M, Lenaers G (2011) OPA1 links human mitochondrial genome maintenance to mtDNA replication and distribution. Genome Res 21:12-20. CrossRef Medline

Flinn L, Mortiboys H, Volkmann K, Köster RW, Ingham PW, Bandmann O (2009) Complex I deficiency and dopaminergic neuronal cell loss in parkin-deficient zebrafish (Danio rerio). Brain 132:1613-1623. CrossRef Medline

Fukui H, Moraes CT (2009) Mechanisms of formation and accumulation of mitochondrial DNA deletions in aging neurons. Hum Mol Genet 18: 1028-1036. CrossRef Medline

Furda AM, Bess AS, Meyer JN, Van Houten B (2012) Analysis of DNA damage and repair in nuclear and mitochondrial DNA of animal cells using quantitative PCR. Methods Mol Biol 920:111-132. CrossRef Medline

Gaweda-Walerych K, Zekanowski C (2013) Integrated pathways of parkin control over mitochondrial maintenance-relevance to Parkinson's disease pathogenesis. Acta Neurobiol Exp (Wars) 73:199-224. Medline

Goldberg MS, Fleming SM, Palacino JJ, Cepeda C, Lam HA, Bhatnagar A, Meloni EG, Wu N, Ackerson LC, Klapstein GJ, Gajendiran M, Roth BL, Chesselet MF, Maidment NT, Levine MS, Shen J (2003) Parkindeficient mice exhibit nigrostriatal deficits but not loss of dopaminergic neurons. J Biol Chem 278:43628-43635. CrossRef Medline

Greene JC, Whitworth AJ, Kuo I, Andrews LA, Feany MB, Pallanck LJ (2003) Mitochondrial pathology and apoptotic muscle degeneration in Drosophila parkin mutants. Proc Natl Acad Sci U S A 100:4078-4083. CrossRef Medline

Grünewald A, Rygiel KA, Hepplewhite PD, Morris CM, Picard M, Turnbull DM (2016) Mitochondrial DNA depletion in respiratory chain-deficient Parkinson disease neurons. Ann Neurol 79:366-378. CrossRef Medline

Hara T, Nakamura K, Matsui M, Yamamoto A, Nakahara Y, SuzukiMigishima R, Yokoyama M, Mishima K, Saito I, Okano H, Mizushima N (2006) Suppression of basal autophagy in neural cells causes neurodegenerative disease in mice. Nature 441:885-889. CrossRef Medline

Hattori N, Kitada T, Matsumine H, Asakawa S, Yamamura Y, Yoshino H, Kobayashi T, Yokochi M, Wang M, Yoritaka A, Kondo T, Kuzuhara S, Nakamura S, Shimizu N, Mizuno Y (1998) Molecular genetic analysis of a novel Parkin gene in Japanese families with autosomal recessive juvenile parkinsonism: evidence for variable homozygous deletions in the Parkin gene in affected individuals. Ann Neurol 44:935-941. CrossRef Medline

Jiang H, Jiang Q, Feng J (2004) Parkin increases dopamine uptake by enhancing the cell surface expression of dopamine transporter. J Biol Chem 279:54380-54386. CrossRef Medline

Jiang H, Jiang Q, Liu W, Feng J (2006) Parkin suppresses the expression of monoamine oxidases. J Biol Chem 281:8591-8599. CrossRef

Kageyama Y, Zhang Z, Roda R, Fukaya M, Wakabayashi J, Wakabayashi N, Kensler TW, Reddy PH, Iijima M, Sesaki H (2012) Mitochondrial division ensures the survival of postmitotic neurons by suppressing oxidative damage. J Cell Biol 197:535-551. CrossRef Medline

Kim KY, Stevens MV, Akter MH, Rusk SE, Huang RJ, Cohen A, Noguchi A, Springer D, Bocharov AV, Eggerman TL, Suen DF, Youle RJ, Amar M, Remaley AT, Sack MN (2011) Parkin is a lipid-responsive regulator of fat uptake in mice and mutant human cells. J Clin Invest 121:3701-3712. CrossRef Medline

Kitada T, Asakawa S, Hattori N, Matsumine H, Yamamura Y, Minoshima S, Yokochi M, Mizuno Y, Shimizu N (1998) Mutations in the parkin gene cause autosomal recessive juvenile parkinsonism. Nature 392:605-608. CrossRef Medline

Kitada T, Tong Y, Gautier CA, Shen J (2009) Absence of nigral degeneration in aged parkin/DJ-1/PINK1 triple knockout mice. J Neurochem 111:696702. CrossRef Medline

Koh H, Chung J (2010) PINK1 and Parkin to control mitochondria remodeling. Anat Cell Biol 43:179-184. CrossRef Medline

Kraytsberg Y, Kudryavtseva E, McKee AC, Geula C, Kowall NW, Khrapko K (2006) Mitochondrial DNA deletions are abundant and cause functional impairment in aged human substantia nigra neurons. Nat Genet 38:518 520. CrossRef Medline

LaFrance R, Brustovetsky N, Sherburne C, Delong D, Dubinsky JM (2005) Age-related changes in regional brain mitochondria from Fischer 344 rats. Aging Cell 4:139-145. CrossRef Medline

LaVoie MJ, Ostaszewski BL, Weihofen A, Schlossmacher MG, Selkoe DJ 
(2005) Dopamine covalently modifies and functionally inactivates parkin. Nat Med 11:1214-1221. CrossRef Medline

Lee S, Sterky FH, Mourier A, Terzioglu M, Cullheim S, Olson L, Larsson NG (2012) Mitofusin 2 is necessary for striatal axonal projections of midbrain dopamine neurons. Hum Mol Genet 21:4827-4835. CrossRef Medline

Lee Y, Stevens DA, Kang SU, Jiang H, Lee YI, Ko HS, Scarffe LA, Umanah GE, Kang H, Ham S, Kam TI, Allen K, Brahmachari S, Kim JW, Neifert S, Yun SP, Fiesel FC, Springer W, Dawson VL, Shin JH, et al (2017) PINK1 primes Parkin-mediated ubiquitination of PARIS in dopaminergic neuronal survival. Cell Rep 18:918-932. CrossRef Medline

Maslov AY, Ganapathi S, Westerhof M, Quispe-Tintaya W, White RR, Van Houten B, Reiling E, Dollé ME, van Steeg H, Hasty P, Hoeijmakers JH, Vijg J (2013) DNA damage in normally and prematurely aged mice. Aging Cell 12:467-477. CrossRef Medline

Matsuura K, Kabuto H, Makino H, Ogawa N (1997) Pole test is a useful method for evaluating the mouse movement disorder caused by striatal dopamine depletion. J Neurosci Methods 73:45-48. CrossRef Medline

Meiser J, Weindl D, Hiller K (2013) Complexity of dopamine metabolism. Cell Commun Signal 11:34. CrossRef Medline

Melser S, Chatelain EH, Lavie J, Mahfouf W, Jose C, Obre E, Goorden S, Priault M, Elgersma Y, Rezvani HR, Rossignol R, Bénard G (2013) Rheb regulates mitophagy induced by mitochondrial energetic status. Cell Metab 17:719-730. CrossRef Medline

Meredith GE, Kang UJ (2006) Behavioral models of Parkinson's disease in rodents: a new look at an old problem. Mov Disord 21:1595-1606. CrossRef Medline

Müller-Rischart AK, Pilsl A, Beaudette P, Patra M, Hadian K, Funke M, Peis R, Deinlein A, Schweimer C, Kuhn PH, Lichtenthaler SF, Motori E, Hrelia S, Wurst W, Trümbach D, Langer T, Krappmann D, Dittmar G, Tatzelt J, Winklhofer KF (2013) The E3 ligase parkin maintains mitochondrial integrity by increasing linear ubiquitination of NEMO. Mol Cell 49:908921. CrossRef Medline

Myöhänen TT, Schendzielorz N, Männistö PT (2010) Distribution of catechol-O-methyltransferase (COMT) proteins and enzymatic activities in wild-type and soluble COMT deficient mice. J Neurochem 113:16321643. CrossRef Medline

Narendra DP, Youle RJ (2011) Targeting mitochondrial dysfunction: role for PINK1 and Parkin in mitochondrial quality control. Antioxid Redox Signal 14:1929-1938. CrossRef Medline

Narendra D, Tanaka A, Suen DF, Youle RJ (2008) Parkin is recruited selectively to impaired mitochondria and promotes their autophagy. J Cell Biol 183:795-803. CrossRef Medline

Oyama G, Yoshimi K, Natori S, Chikaoka Y, Ren YR, Funayama M, Shimo Y, Takahashi R, Nakazato T, Kitazawa S, Hattori N (2010) Impaired in vivo dopamine release in parkin knockout mice. Brain Res 1352:214-222. CrossRef Medline

Perez FA, Palmiter RD (2005) Parkin-deficient mice are not a robust model of parkinsonism. Proc Natl Acad Sci U S A 102:2174-2179. CrossRef Medline

Perier C, Bender A, García-Arumí E, Melià MJ, Bové J, Laub C, Klopstock T, Elstner M, Mounsey RB, Teismann P, Prolla T, Andreu AL, Vila M (2013) Accumulation of mitochondrial DNA deletions within dopaminergic neurons triggers neuroprotective mechanisms. Brain 136:23692378. CrossRef Medline

Pickrell AM, Youle RJ (2015) The roles of PINK1, parkin, and mitochondrial fidelity in Parkinson's disease. Neuron 85:257-273. CrossRef Medline

Pickrell AM, Pinto M, Hida A, Moraes CT (2011a) Striatal dysfunctions associated with mitochondrial DNA damage in dopaminergic neurons in a mouse model of Parkinson's disease. J Neurosci 31:17649-17658. CrossRef Medline

Pickrell AM, Fukui H, Wang X, Pinto M, Moraes CT (2011b) The striatum is highly susceptible to mitochondrial oxidative phosphorylation dysfunctions. J Neurosci 31:9895-9904. CrossRef Medline

Pickrell AM, Huang CH, Kennedy SR, Ordureau A, Sideris DP, Hoekstra JG, Harper JW, Youle RJ (2015) Endogenous Parkin preserves dopaminergic substantia nigral neurons following mitochondrial DNA mutagenic stress. Neuron 87:371-381. CrossRef Medline

Poole AC, Thomas RE, Yu S, Vincow ES, Pallanck L (2010) The mitochon- drial fusion-promoting factor mitofusin is a substrate of the PINK1/parkin pathway. PLoS One 5:e10054. CrossRef Medline

Reeve A, Meagher M, Lax N, Simcox E, Hepplewhite P, Jaros E, Turnbull D (2013) The impact of pathogenic mitochondrial DNA mutations on substantia nigra neurons. J Neurosci 33:10790-10801. CrossRef Medline

Rothfuss O, Fischer H, Hasegawa T, Maisel M, Leitner P, Miesel F, Sharma M, Bornemann A, Berg D, Gasser T, Patenge N (2009) Parkin protects mitochondrial genome integrity and supports mitochondrial DNA repair. Hum Mol Genet 18:3832-3850. CrossRef

Santos JH, Meyer JN, Mandavilli BS, Van Houten B (2006) Quantitative PCR-based measurement of nuclear and mitochondrial DNA damage and repair in mammalian cells. Methods Mol Biol 314:183-199. CrossRef Medline

Sarraf SA, Raman M, Guarani-Pereira V, Sowa ME, Huttlin EL, Gygi SP, Harper JW (2013) Landscape of the PARKIN-dependent ubiquitylome in response to mitochondrial depolarization. Nature 496:372-376. CrossRef Medline

Schapira AH, Cooper JM, Dexter D, Clark JB, Jenner P, Marsden CD (1990a) Mitochondrial complex I deficiency in Parkinson's disease. J Neurochem 54:823-827. CrossRef Medline

Schapira AH, Mann VM, Cooper JM, Dexter D, Daniel SE, Jenner P, Clark JB, Marsden CD (1990b) Anatomic and disease specificity of NADH CoQ1 reductase (complex I) deficiency in Parkinson's disease. J Neurochem 55: 2142-2145. CrossRef Medline

Schmittgen TD, Livak KJ (2008) Analyzing real-time PCR data by the comparative C(T) method. Nat Protoc 3:1101-1108. CrossRef Medline

Shin JH, Ko HS, Kang H, Lee Y, Lee YI, Pletinkova O, Troconso JC, Dawson VL, Dawson TM (2011) PARIS (ZNF746) repression of PGC-1alpha contributes to neurodegeneration in Parkinson's disease. Cell 144:689_ 702. CrossRef Medline

Song L, McMackin M, Nguyen A, Cortopassi G (2017) Parkin deficiency accelerates consequences of mitochondrial DNA deletions and Parkinsonism. Neurobiol Dis 100:30-38. CrossRef Medline

Srivastava S, Moraes CT (2005) Double-strand breaks of mouse muscle mtDNA promote large deletions similar to multiple mtDNA deletions in humans. Hum Mol Genet 14:893-902. CrossRef Medline

Sterky FH, Lee S, Wibom R, Olson L, Larsson NG (2011) Impaired mitochondrial transport and Parkin-independent degeneration of respiratory chain-deficient dopamine neurons in vivo. Proc Natl Acad Sci U S A 108: 12937-12942. CrossRef Medline

Stevens DA, Lee Y, Kang HC, Lee BD, Lee YI, Bower A, Jiang H, Kang SU, Andrabi SA, Dawson VL, Shin JH, Dawson TM (2015) Parkin loss leads to PARIS-dependent declines in mitochondrial mass and respiration. Proc Natl Acad Sci U S A 112:11696-11701. CrossRef Medline

Suen DF, Narendra DP, Tanaka A, Manfredi G, Youle RJ (2010) Parkin overexpression selects against a deleterious mtDNA mutation in heteroplasmic cybrid cells. Proc Natl Acad Sci U S A 107:11835-11840. CrossRef Medline

Tanaka A, Cleland MM, Xu S, Narendra DP, Suen DF, Karbowski M, Youle RJ (2010) Proteasome and p97 mediate mitophagy and degradation of mitofusins induced by Parkin. J Cell Biol 191:1367-1380. CrossRef Medline

Vaughan RA, Foster JD (2013) Mechanisms of dopamine transporter regulation in normal and disease states. Trends Pharmacol Sci 34:489-496. CrossRef Medline

Vincow ES, Merrihew G, Thomas RE, Shulman NJ, Beyer RP, MacCoss MJ, Pallanck LJ (2013) The PINK1-Parkin pathway promotes both mitophagy and selective respiratory chain turnover in vivo. Proc Natl Acad Sci U S A 110:6400-6405. CrossRef Medline

Von Coelln R, Thomas B, Savitt JM, Lim KL, Sasaki M, Hess EJ, Dawson VL, Dawson TM (2004) Loss of locus coeruleus neurons and reduced startle in parkin null mice. Proc Natl Acad Sci U S A 101:10744-10749. CrossRef Medline

Wang X, Winter D, Ashrafi G, Schlehe J, Wong YL, Selkoe D, Rice S, Steen J, LaVoie MJ, Schwarz TL (2011) PINK1 and Parkin target Miro for phosphorylation and degradation to arrest mitochondrial motility. Cell 147: 893-906. CrossRef Medline

Ziviani E, Tao RN, Whitworth AJ (2010) Drosophila parkin requires PINK1 for mitochondrial translocation and ubiquitinates mitofusin. Proc Natl Acad Sci U S A 107:5018-5023. CrossRef Medline 